\title{
The performance of Aeolus in heterogeneous atmospheric conditions using high-resolution radiosonde data
}

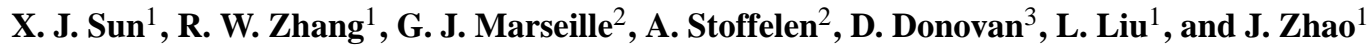 \\ ${ }^{1}$ College of Meteorology and Oceanography, PLA University of Science and Technology, Nanjing, China \\ ${ }^{2}$ Weather Research Department of the Royal Netherlands Meteorological Institute, De Bilt, the Netherlands \\ ${ }^{3}$ Regional Climate Department of the Royal Netherlands Meteorological Institute, De Bilt, the Netherlands
}

Correspondence to: R. W. Zhang (weishen365@gmail.com)

Received: 24 October 2013 - Published in Atmos. Meas. Tech. Discuss.: 12 February 2014

Revised: 16 May 2014 - Accepted: 3 July 2014 - Published: 26 August 2014

\begin{abstract}
The European Space Agency Aeolus mission aims to measure wind profiles from space. A major challenge is to retrieve high quality winds in heterogeneous atmospheric conditions, i.e. where both the atmospheric dynamics and optical properties vary strongly within the sampling volume. In preparation for launch we aim to quantify the expected error of retrieved winds from atmospheric heterogeneity, particularly in the vertical, and develop algorithms for wind error correction, as part of the level-2B processor (L2Bp).

We demonstrate that high-resolution data from radiosondes provide valuable input to establish a database of collocated wind and atmospheric optics at $10 \mathrm{~m}$ vertical resolution to simulate atmospheric conditions along Aeolus' lines of sight. The database is used to simulate errors of Aeolus winds retrieved from the Mie and Rayleigh channel signals. The non-uniform distribution of molecules in the measurement bin introduces height assignment errors in Rayleigh channel winds up to $2.5 \%$ of the measurement bin size in the stratosphere which translates to $0.5 \mathrm{~m} \mathrm{~s}^{-1}$ bias for typical atmospheric conditions, if not corrected. The presence of cloud or aerosol layers in the measurement bin yields biases in Mie channel winds which cannot be easily corrected and mostly exceed the mission requirement of $0.4 \mathrm{~m} \mathrm{~s}^{-1}$. The collocated Rayleigh channel wind solution is generally preferred because of smaller biases, in particular for transparent cloud and aerosol layers with one-way transmission above 0.8 .

The results show that Aeolus L2Bp, under development, can be improved by the estimation of atmosphere optical properties to correct for height assignment errors and to identify wind solutions potentially detrimental when used in $\mathrm{Nu}$ merical Weather Prediction.
\end{abstract}

\section{Introduction}

The largest spatial variations of the wind generally occur in the vertical, but only few global profile measurements exist today to measure these variations across the globe. The noted variations, i.e. vertical gradient of horizontal wind (wind shear), cause mixing of air and thus describe the vertical exchange of the associated air properties of momentum, heat, humidity and cloud particles. Indeed, vertical profile of horizontal wind and its shear may indicate dynamical atmospheric processes often associated with cloud formation and significant weather. Such processes generally cause heterogeneous optical properties of the atmosphere, both horizontally and vertically. It remains a challenge to simultaneously measure wind and atmospheric property profiles across the globe.

The European Space Agency (ESA) Aeolus mission aims to measure wind profiles from space from the received backscatter signal by atmospheric particles (aerosol and cloud) and molecules. However, retrieved winds may suffer from biases induced by instrument imperfections and heterogeneous atmospheric conditions, i.e. varying backscatter and wind inside Aeolus measurement volumes (bins), while observation biases are known to be detrimental when gone undetected in numerical weather prediction (NWP) data assimilation. In preparation for Aeolus this study aims to quantify the expected bias of Aeolus winds caused by vertical atmospheric heterogeneity. In addition recommendations are formulated to identify such scenes and apply quality control to improve level-2B processing before using the observations in NWP. A detailed description of Aeolus is provided in Sect. 2. 
Realistic assessment of Aeolus wind errors from atmospheric heterogeneity requires a database of combined wind and atmosphere optical properties at substantially higher resolution than the Aeolus observation sampling volume, which is typically $86 \mathrm{~km}$ along satellite track and several hundreds of metres to $2 \mathrm{~km}$ in the vertical. Data from observation sites or available databases either lack resolution or one of the needed database ingredients.

The atmospheric database described in Marseille et al. (2011) is composed of atmospheric backscatter and extinction at $355 \mathrm{~nm}$ retrieved from CALIPSO attenuated backscatter at $532 \mathrm{~nm}$ and atmospheric dynamics and temperature from the ECMWF global model interpolated to the CALIPSO track. The horizontal and vertical sampling of the database is 3.5 and $125 \mathrm{~m}$, respectively. However, the effective resolution of NWP models is substantially lower. The horizontal resolution of the ECMWF model is typically 15-20 times the model grid size in the free troposphere (Vogelzang et al., 2011; Marseille et al., 2013). Houchi et al. (2010) found the vertical resolution of the 2007 model version to be about $1.7 \mathrm{~km}$, i.e. substantially coarser than the spacing between model levels. As a consequence, the Marseille et al. (2011) database substantially underestimates the wind variability within Aeolus samples.

Radiosondes provide wind information at about $10 \mathrm{~m}$ vertical resolution from the launch location up to about $30 \mathrm{~km}$ altitude along the radiosonde track (Houchi et al., 2010). Radiosonde winds thus very well simulate the wind variability in the vertical as observed (integrated) by Aeolus. Here, we ignore the horizontal variability of the wind within the sampling volume along the Aeolus track, with only limited loss of generality. After all, the Aeolus horizontal integration length is oversampled, i.e. typically 30 measurements are available for an integrated observation as described in Sect. 2. This provides information on the atmospheric heterogeneity along the track, e.g. large signal variations in turbulent regions or near frontal zones may be detected, and the classification procedure of the L2Bp (Tan et al., 2008) is used to apply quality control (QC) and horizontally integrate these measurements in an optimal way to observation level. Generally, no oversampling is done in the vertical, and thus means for QC are limited, if possible at all, making Aeolus winds most sensitive to errors from heterogeneity in the vertical.

Section 3 provides an analytical calculation of Aeolus wind errors due to vertical heterogeneity of the atmosphere. These are complemented with calculations from real atmospheric scenes as derived from a database of radiosondes launched in De Bilt, the Netherlands, in 2007. High resolution CALIPSO data are potentially useful to complete radiosonde database with cloud and aerosol backscatter and extinction. However, they appeared not suitable in this study for reasons discussed in Sect. 4. Instead, the method of Zhang et al. (2010) to detect cloud layers along a radiosonde path is adopted. To complete the atmospheric backscatter profile, aerosol backscatter along the radiosonde path is simulated from a climatological aerosol backscatter profile and radiosonde humidity. The resulting radiosonde database of wind, temperature, relative humidity, and aerosol/cloud backscatter and extinction at $10 \mathrm{~m}$ vertical resolution is validated in Sect. 5 and used in Sect. 6 as input for the Lidar Performance Analysis Simulator (LIPAS) (Marseille and Stoffelen, 2003) to estimate wind errors induced by atmospheric heterogeneity. Section 7 concludes with the summary and main conclusions.

\section{The Aeolus mission}

The ESA Aeolus mission to measure wind profiles from space is scheduled for launch in the second half of 2015. Aeolus is a sun-synchronous dawn-dusk polar-orbiting satellite that carries a Doppler wind lidar with a fixed line of sight (LOS) pointing towards the atmosphere at $35^{\circ}$ off-nadir and $90^{\circ}$ across the satellite ground track on the earth surface, away from the sun. As such, Aeolus measures a single LOS wind component rather than the complete wind vector. The lidar is operated in the ultraviolet (UV) part of the electromagnetic spectrum at $355 \mathrm{~nm}$ laser wavelength. At this wavelength, atmospheric scattering applies to both particles (aerosols, cloud droplets) and molecules. The combined spectrally broad Rayleigh (molecular) signal and spectrally thin Mie (particle) signal are separated by the instrument receiver hardware (ESA, 2008), potentially yielding two wind solutions for the sampled volume, from the Mie and Rayleigh channel signals, respectively.

The return signal from the atmosphere is divided in sequential time intervals that determine the vertical (range gate) resolution of the retrieved wind profile. The number of vertical bins is limited by instrument hardware to 24 for both Mie and Rayleigh channels with minimum and maximum vertical bin sizes of 250 and $2000 \mathrm{~m}$, respectively. Intermediate bin sizes are limited to multiples of $250 \mathrm{~m}$. The mission requirement for the horizontally projected line of sight (HLOS) (Marseille and Stoffelen, 2003) wind error standard deviation of $1-2 \mathrm{~m} \mathrm{~s}^{-1}$ in the boundary layer, $2-3 \mathrm{~m} \mathrm{~s}^{-1}$ in the free troposphere and $3-5 \mathrm{~m} \mathrm{~s}^{-1}$ in the lower stratosphere (ESA, 2008) is achieved for bin sizes of typically $250-500 \mathrm{~m}$ in the boundary layer, $1 \mathrm{~km}$ in the free troposphere and $2 \mathrm{~km}$ in the lower stratosphere. The maximum bin altitude is about $32 \mathrm{~km}$ which is mainly driven by signal-to-noise ratio (SNR) considerations to yield Rayleigh channel winds that meet the mission requirements up to the lower stratosphere.

In 2010 it was decided to change operation from burst pulsed-laser mode (BM) to continuous pulsed-laser mode $(\mathrm{CM})$, i.e. the instrument will be no longer switched on in measurement cycles of $7 \mathrm{~s}$ alternated by being switched off for $21 \mathrm{~s}$ (Stoffelen et al., 2005). As a compromise and to meet the instrument energy budget, the laser pulse repetition frequency was decreased from 100 to $50 \mathrm{~Hz}$. As such, the amount of energy emitted into the atmosphere is about 
doubled when changing from $\mathrm{BM}$ to $\mathrm{CM}$, which may be profitable.

The Aeolus CM sampling is characterized by a so-called basic repeat cycle (BRC) of $12 \mathrm{~s}$, which translates to segments of about $86.4 \mathrm{~km}$ length along the satellite track for a satellite ground speed of about $7.2 \mathrm{~km} \mathrm{~s}^{-1}$. The atmospheric signal scattered back to the instrument is collected and accumulated at $0.4 \mathrm{~s}$ intervals, i.e. corresponding to 20 shots or $2.88 \mathrm{~km}$ along track. These samples are denoted measurements. A BRC is thus composed of 30 measurements. These measurements are broadcast to the ground segment for processing and wind retrieval (ESA, 2008; Tan et al., 2008).

In preparation for the Aeolus mission a number of activities have been conducted over more than a decade including the definition of atmospheric databases (Vaughan et al., 1998; Houchi et al., 2010; Marseille et al., 2011), instrument simulation (Marseille and Stoffelen, 2003), airborne demonstration (Schillinger et al., 2003; Ansmann et al., 2006; Reitebuch et al., 2009; Paffrath et al., 2009), impact assessment for NWP (Stoffelen et al., 2006; Tan et al., 2007; Marseille et al., 2008) and the development of the ground segment processors (Tan et al., 2008). The quality of Aeolus winds is largely determined by the (random) instrument noise and the variability of the atmospheric dynamics and optical properties within the sampling volume of typically $80-$ $100 \mathrm{~km}$ along track and $1 \mathrm{~km}$ vertically. Atmospheric heterogeneity may cause substantial systematic errors in the case of substantial wind shear in combination with a heterogeneous distribution of particles inside the sampling volume. Observation biases are known to be detrimental when gone undetected in NWP. Aeolus processing equipment should therefore be prepared to detect heterogeneous atmospheric scenes and take measures, e.g. include information that allows users to reject or reduce the weight of observations when used in NWP. The development of processing algorithms profits from an atmospheric database at high resolution, i.e. substantially higher than the Aeolus sampling, to realistically simulate Aeolus performance in heterogeneous atmospheric conditions. Radiosondes provide input for such a database as discussed in Sect. 4 after the analytical assessment in Sect. 3.

\section{Aeolus wind errors from atmospheric heterogeneity; an analytical assessment}

A single Aeolus wind observation corresponds to an atmospheric slice with dimensions of typically $50-100 \mathrm{~km}$ along track (horizontal) and $1 \mathrm{~km}$ in the vertical. Typical values for 1 range from 0.25 to 2 . The along-track observation length is subdivided by typically 30 measurements, as described in Sect. 2. The Aeolus L2Bp includes a classification module that provides representative weights to the measurements, based on the measured horizontal optical heterogeneity, before integration to an observation (Tan et al., 2008). Since algorithms exist to control the along-track integration of the received atmospheric signal, it is expected that the wind error induced through atmospheric heterogeneity in the horizontal is small as compared to the wind error associated with the integrated atmospheric heterogeneity in the vertical. Without additional information, e.g. from other sensors or models, we lack knowledge on the exact distribution of particles inside the vertical measurement bin. The measured wind from particles (Mie channel) or molecules (Rayleigh channel) inside the measurement bin, denoted $u_{\mathrm{p}}^{\mathrm{M}}$ and $u_{\mathrm{m}}^{\mathrm{M}}$ respectively, can in general be written as a weighted average, denoted by $w$, of the true wind $u$ inside the bin of length $l$ as follows:

$$
u_{k}^{\mathrm{M}}=\frac{\int_{z_{0}}^{z_{l}} w_{k}(z) u(z) \mathrm{d} z}{\int_{z_{0}}^{z_{l}} w_{k}(z) \mathrm{d} z}, k=\{\mathrm{p}, \mathrm{m}\}
$$

with $z$ denoting altitude and $z_{0}$ and $z_{l}$ denoting the bottom and top altitude of the vertical bin, respectively. Assigning the measured wind to the centre of the measurement bin introduces an error when particles and/or molecules, or more precisely the weight functions $w_{k}$ in Eq. (1), are not uniformly distributed inside the bin, which is generally the case. The most representative location of the measured wind in the measurement bin, also denoted the centre-of-gravity (COG) location and denoted $H_{k}^{\mathrm{M}}$, is related to the distribution of the scattering particles and/or molecules inside the measurement bin:

$$
H_{k}^{\mathrm{M}}\left(z_{0}, z_{l}\right)=\frac{\int_{z_{0}}^{z_{l}} z w_{k}(z) \mathrm{d} z}{\int_{z_{0}}^{z_{l}} w_{k}(z) \mathrm{d} z}, k=\{\mathrm{p}, \mathrm{m}\} .
$$

The following sections discuss the potential of estimating the COG location of Aeolus winds for two hypothetical atmospheric scenes.

\subsection{Particle-free atmosphere}

Following Vaughan (2002, p. 939), molecular scattering is a function of atmospheric temperature and pressure which are available in the Aeolus L2Bp. Molecular backscatter, $\beta_{\mathrm{m}}(z, \lambda)\left(\mathrm{m}^{-1} \mathrm{sr}^{-1}\right)$, can be modelled by an exponentially decreasing function as a function of altitude $z$ :

$\beta_{\mathrm{m}}(z, \lambda)=10^{-7}\left(\frac{\lambda_{0}}{\lambda}\right)^{4.09} e^{-z / z_{\mathrm{mol}}}$

with $\lambda_{0}$ the reference wavelength of $1.06 \mu \mathrm{m}, \lambda$ the instrument wavelength, i.e. $355 \mathrm{~nm}$ for Aeolus and reference height $z_{\mathrm{mol}}=8000 \mathrm{~m}$. Equation (3) is a simplification, not taking into account actual air temperature and pressure, but is convenient for an analytical evaluation in this section. The proximity of Eq. (3) is further discussed in Sect. 6. For convenience we remove $\lambda$ from the variable argument list. For 

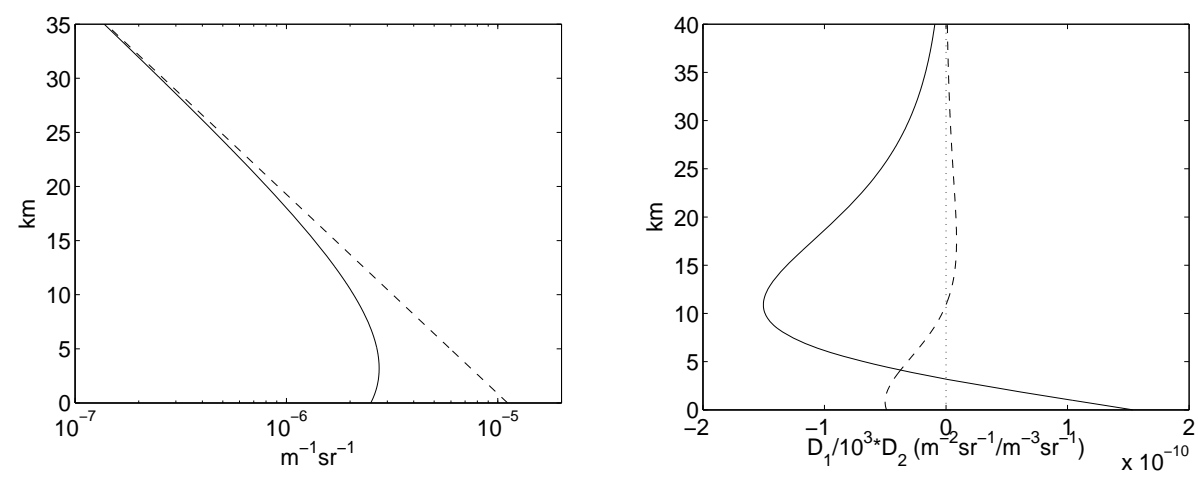

Figure 1. Left panel: molecular backscatter (dashed) and attenuated molecular backscatter, i.e. the weight function (solid). Right panel: weight function first-order ( $D_{1}$, solid) and second-order derivatives ( $D_{2}$ multiplied by 1000 , dashed), see Eq. (8).

an atmosphere free of particles, the weight function $w_{\mathrm{m}}$ in Eqs. (1) and (2) equals the attenuated molecular backscatter profile:

$w_{\mathrm{m}}(z)=\beta_{\mathrm{m}}^{\prime}(z)=\beta_{\mathrm{m}}(z) \tau_{\mathrm{m}}^{2}(z)$

with $\tau_{\mathrm{m}}(z)$ the total one-way atmospheric transmission of the laser light between the instrument and altitude $z$, above the earth surface that decreases when penetrating deeper into the troposphere through molecular backscatter and absorption. Signal transmission is calculated from

$\tau_{\mathrm{m}}(z)=\exp \left[-\int_{z}^{\infty} \sigma_{\mathrm{m}}\left(z^{\prime}\right) \mathrm{d} z^{\prime}\right]$

with $\sigma_{\mathrm{m}}(z)\left(\mathrm{m}^{-1}\right)$ molecular extinction which is related to molecular backscatter by Rayleigh scattering theory (e.g. Vaughan, 2002) through

$\sigma_{\mathrm{m}}(z)=8 \pi / 3 \beta_{\mathrm{m}}(z)$.

Substituting Eqs. (6) and (3) into Eq. (5), solving the integral and after some rearranging yields

$w_{\mathrm{m}}(z)=\beta_{\mathrm{m}}^{\prime}(z)=\beta_{\mathrm{m}}(z) e^{-k \beta_{\mathrm{m}}(z)}$

with $k=16 \pi z_{\mathrm{mol}} / 3\left(\mathrm{~m} \mathrm{sr}^{-1}\right)$. The left panel in Fig. 1 shows that attenuated molecular backscatter, Eq. (7), starts to deviate from the backscatter profile, Eq. (3), at about $30 \mathrm{~km}$ altitude. The maximum value is reached at $3.2 \mathrm{~km}$ giving maximum Rayleigh channel signal at this altitude.

To calculate the integrals in Eq. (2) using Eq. (7), a secondorder Taylor expansion is applied to Eq. (7) near the bin centre $z^{*}=\left(z_{l}+z_{0}\right) / 2$ :

$$
\begin{gathered}
w_{\mathrm{m}}(z) \approx w_{\mathrm{m}}\left(z^{*}\right)+D_{1}\left(z^{*}\right)\left(z-z^{*}\right)+\frac{1}{2} D_{2}\left(z^{*}\right)\left(z-z^{*}\right)^{2} \\
D_{i}(z)=\frac{d^{i} w_{\mathrm{m}}(z)}{\mathrm{d} z^{i}}, \quad i=\{1,2\}
\end{gathered}
$$

with $D_{i}$ denoting the $i$ th-order derivative of the weight function (Eq. 7). The right panel of Fig. 1 shows that the amplitude of the second-order derivative is substantially smaller than the amplitude of the first-order derivative and it was verified that ignoring the second-order term in the Taylor expansion has negligible impact on the result for the typical measurement bin sizes of Aeolus (not shown). Substituting Eq. (8) into Eq. (2), setting $D_{2}$ equal to zero and solving the integrals yields for the measurement bin COG location:

$$
\begin{aligned}
H_{\mathrm{m}}^{\mathrm{M}}\left(z_{0}, z_{l}\right)= & z^{*}+\frac{D_{1}\left(z^{*}\right) l^{2}}{12 w_{\mathrm{m}}\left(z^{*}\right)} \\
& z^{*}=\left(z_{l}+z_{0}\right) / 2, l=z_{l}-z_{0} .
\end{aligned}
$$

From Eq. (9), it is clear that the COG location does not coincide with the bin centre location $z^{*}$, in general. The second term on the right-hand side of Eq. (9) is denoted the height assignment error, $\Delta H(\mathrm{~m})$.

The Rayleigh channel height assignment error was calculated for three typical bin sizes $l=\{1000,1500,2000 \mathrm{~m}\}$ and the typical altitude range of Aeolus winds between the surface and about $35 \mathrm{~km}$. Figure 2 shows that the height assignment error is smaller near the earth surface. At about $2.2 \mathrm{~km}$ (rather than at $3.2 \mathrm{~km}$ because the weight function is asymmetric near its maximum) the height assignment error equals zero and reverses sign.

Aeolus measurement bin size is not fixed and may be adapted with a maximum of eight times per orbit. The typical bin size for the Rayleigh channel is $1000 \mathrm{~m}$ below $16 \mathrm{~km}$ altitude and $1500-2000 \mathrm{~m}$ above $16 \mathrm{~km}$ altitude. From Fig. 2 it is concluded that the typical height assignment error for Rayleigh channel winds increases with altitude: (i) $\Delta H<10 \mathrm{~m}$ for $1000 \mathrm{~m}$ bins below $16 \mathrm{~km}$ altitude, i.e. less than $1 \%$, (ii) $\Delta H \approx 20 \mathrm{~m}$ for $1500 \mathrm{~m}$ bins, typically between 16 and $25 \mathrm{~km}$ altitude, i.e. slightly above $1 \%$ and (iii) $\Delta H \approx 40 \mathrm{~m}$ for $2000 \mathrm{~m}$ bins above $25 \mathrm{~km}$ altitude, i.e. about $2 \%$. Figure 2 may be used as a baseline to correct for height assignment errors of Aeolus Rayleigh channel winds in atmospheric scenes that are free of particles. 


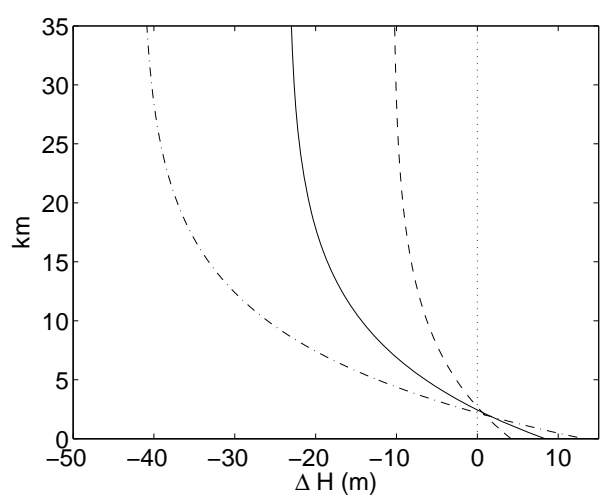

Figure 2. Aeolus Rayleigh channel height assignment error, $\Delta H$, for a particle-free atmosphere and measurement bin size of $1000 \mathrm{~m}$ (dashed), $1500 \mathrm{~m}$ (solid) and $2000 \mathrm{~m}$ (dash-dotted). The dotted line denotes $\Delta H$ equal to zero.

A bias is introduced in the Aeolus wind observation, if not corrected for the height assignment error. For a linearly increasing wind (wind shear) within the measurement bin of amplitude $\alpha\left(\mathrm{s}^{-1}\right)$, the wind error bias equals $\alpha \Delta H$. For a typical wind shear in the free troposphere of $0.01 \mathrm{~s}^{-1}$ $\left(10 \mathrm{~m} \mathrm{~s}^{-1}\right.$ per $\left.\mathrm{km}\right)$ (Houchi et al., 2010), the wind error bias is below $0.1 \mathrm{~m} \mathrm{~s}^{-1}$ below $16 \mathrm{~km}$, slightly more than $0.2 \mathrm{~m} \mathrm{~s}^{-1}$ between 16 and $25 \mathrm{~km}$ and about $0.4 \mathrm{~m} \mathrm{~s}^{-1}$ above $25 \mathrm{~km}$. These numbers are small, not exceeding the mission bias requirement of $0.4 \mathrm{~m} \mathrm{~s}^{-1}$ (ESA, 2008). However, much larger wind shear values in the order of $0.05 \mathrm{~s}^{-1}$ may be found near the planetary boundary layer (PBL) and tropopause as a consequence of the typically narrow vertical scales of the PBL and jet stream (Houchi et al., 2010). Moreover, dynamical and optical heterogeneity may be correlated in the atmosphere, aggravating these biases. If not corrected for the height assignment error, resulting wind biases are then of the order of a metre a second.

\subsection{Atmospheric scene with particle layer}

In the case of a particle (cloud or aerosol) layer, of thickness $\delta z$, positioned inside the measurement bin, Aeolus provides two wind solutions, one from the Mie channel which measures the signal backscattered from the particle layer and one from the Rayleigh channel which measures the signal backscattered from molecules inside the bin. Here we assume that the instrument can perfectly separate the Mie and Rayleigh signals or that cross-talk (signal from particles contaminating the molecular signal and vice versa) can be corrected for, e.g. through the optical properties code under development as part of the L2Bp.

Following the procedure of the previous section, the weight function $w_{k}$ for the Mie $(k=\mathrm{p})$ and Rayleigh $(k=\mathrm{m})$ channel equals the attenuated particle and molecular backscatter inside the measurement bin, respectively:

$$
\begin{aligned}
w_{k}(z) & =\beta_{k}^{\prime}(z) \\
& =\beta_{k}(z) \tau^{2}(z) \\
& =\beta_{k}(z) \tau_{\mathrm{m}}^{2}(z) \tau_{\mathrm{p}}^{2}(z) ; k=\{\mathrm{p}, \mathrm{m}\}
\end{aligned}
$$

with $\tau(z)$ the total one-way atmospheric transmission that equals the product of particle and molecular transmission, denoted $\tau_{\mathrm{p}}$ and $\tau_{\mathrm{m}}$, respectively.

For convenience we focus the discussion on a cloud layer of thickness $\delta z$ centred at location $z_{\mathrm{c}}$ and oneway transmission $\tau_{\mathrm{c}}$, and the discussion easily extends to aerosol layers. From Eq. (10) the Mie channel weight function $w_{\mathrm{p}}(z)$ then equals 0 outside the cloud layer, i.e. for $z_{0} \leq z<z_{\mathrm{c}}-\delta z / 2$ and $z_{\mathrm{c}}+\delta z / 2<z \leq z_{l}$, and a linearly decaying $\beta_{\mathrm{p}}^{\prime}(z)$ is assumed inside the cloud layer: $w_{\mathrm{p}}(z)=a z+b$ for $z_{\mathrm{c}}-\delta z / 2 \leq z \leq z_{\mathrm{c}}+\delta z / 2$ with $a=\left(1-\tau_{\mathrm{c}}^{2}\right) / \delta z$ and $b=1-a\left(z_{\mathrm{c}}+\delta z / 2\right)$. Substituting in Eq. (2) and solving the integrals yields for the COG of the measured Mie wind:

$H_{\mathrm{p}}^{\mathrm{M}}\left(z_{\mathrm{c}}\right)=z_{\mathrm{c}}+\frac{\delta z}{6} \frac{\left(1-\tau_{\mathrm{c}}^{2}\right)}{\left(1+\tau_{\mathrm{c}}^{2}\right)}$.

In contrast to the particle-free scene discussed in the previous section, additional information to determine the COG location inside the measurement bin is lacking. More in particular, the cloud location inside the bin and its thickness are unknown and the L2Bp has currently no options to determine these from the measured signals. The cloud location, $z_{\mathrm{c}}$, has equal probability for all locations inside the measurement bin, but is limited to the interval $\left[z_{0}+\delta z / 2, z_{l}-\delta z / 2\right]$ to ensure that the cloud layer is located completely inside the measurement bin. The probability of $z_{\mathrm{c}}$ can thus be modelled through a uniform probability density function with amplitude $(l-\delta z)^{-1}$ with expectation value $(\mu)$, and variance $\left(\sigma^{2}\right)$ :

$\mu\left(z_{\mathrm{c}}\right)=z^{*} ; \sigma^{2}\left(z_{\mathrm{c}}\right)=(l-\delta z)^{2} / 12$

with $z^{*}$ the bin centre location defined in Eq. (9). The expectation value and variance of the COG of the measured Mie wind then equals, from Eqs. (11) and (12),

$\mu\left(H_{\mathrm{p}}^{\mathrm{M}}\right)=z^{*}+\frac{\delta z}{6} \frac{\left(1-\tau_{\mathrm{c}}^{2}\right)}{\left(1+\tau_{\mathrm{c}}^{2}\right)}$

$\sigma^{2}\left(H_{\mathrm{p}}^{\mathrm{M}}\right)=\frac{(l-\delta z)^{2}}{12}$.

The height assignment error, $\Delta H_{\mathrm{p}}^{\mathrm{M}}$, is a stochastic variable which equals $H_{\mathrm{p}}^{\mathrm{M}}\left(z_{\mathrm{c}}\right)-z^{*}$. From Eq. (13) the Mie channel height assignment error bias is a function of the particle layer thickness and transmission. The bias equals zero for a cloud layer of hypothetical infinitesimal small thickness $(\delta z=0)$ or that is fully transparent $\left(\tau_{\mathrm{c}}=1\right)$. The height assignment error variance is independent of the cloud layer transmission, and 
decreases with increasing layer thickness with zero value if the particle layer covers the complete bin, consistent with the single possible realization of such a scene. The bias then reaches its maximum value.

For the Rayleigh channel the weight function is determined by the attenuated molecular backscatter inside the measurement bin, i.e. Eq. (10) with $k=\mathrm{m}$. The contribution of $\beta_{\mathrm{m}}(z) \tau_{\mathrm{m}}^{2}(z)$ was discussed in the previous section and is now assumed constant inside the measurement bin for simplicity with value $w_{0}$ to make the analysis independent of the location of the bin in the vertical profile. The weight function then equals $w_{0}$ above the cloud and $w_{0} \tau_{\mathrm{c}}^{2}$ below the cloud. Inside the cloud layer, the same linear trend as adopted for the Mie channel is used. Substituting in Eq. (2) and solving the integrals yields for the COG of the measured Rayleigh wind:

$H_{\mathrm{m}}^{\mathrm{M}}\left(z_{\mathrm{c}}\right)=\frac{1}{2} \frac{\left(\tau_{\mathrm{c}}^{2}-1\right) z_{\mathrm{c}}^{2}+\left(\tau_{\mathrm{c}}^{2}-1\right) \delta z^{2} / 12+l^{2}}{\left(\tau_{\mathrm{c}}^{2}-1\right) z_{\mathrm{c}}+l}$

where we used $z_{0}=0$ and $z_{l}=1$ in the calculations for convenience, which is valid by the introduction of the constant $w_{0}$. Consequently $z^{*}=1 / 2$ and the height assignment error, $\Delta H_{\mathrm{m}}^{\mathrm{M}}=H_{\mathrm{m}}^{\mathrm{M}}\left(z_{\mathrm{c}}\right)-z^{*}$, equals

$$
\Delta H_{\mathrm{m}}^{\mathrm{M}}\left(z_{\mathrm{c}}\right)=\frac{1}{2}\left[\frac{\left(\tau_{\mathrm{c}}^{2}-1\right) z_{\mathrm{c}}^{2}+\left(\tau_{\mathrm{c}}^{2}-1\right) \delta z^{2} / 12+l^{2}}{\left(\tau_{\mathrm{c}}^{2}-1\right) z_{\mathrm{c}}+l}-l\right] .
$$

For a hypothetical cloud layer of infinitesimal small thickness $(\delta z=0)$ and positioned at the top $\left(z_{\mathrm{c}}=z_{l}=1\right)$ or bottom $\left(z_{\mathrm{c}}=z_{0}=0\right)$ of the measurement bin the height assignment error from Eq. (15) equals zero, independent of the cloud layer transmission. For these particular scenes the Rayleigh channel signal inside the bin is equal to the particle-free case discussed in the previous section. The result is in agreement with Eq. (9) by noting that the introduced simplification of using a constant value $w_{0}$ for $\beta_{\mathrm{m}}(z) \tau_{\mathrm{m}}^{2}(z)$ yields $D_{1}\left(z^{*}\right)=0$ from Eq. (8). Also, the height assignment error equals zero for a virtual fully transparent cloud. A first-order Taylor expansion of the stochastic variable $\Delta H_{\mathrm{m}}^{\mathrm{M}}\left(z_{\mathrm{c}}\right)$ yields

$$
\begin{aligned}
\Delta H_{\mathrm{m}}^{\mathrm{M}}\left(z_{\mathrm{c}}\right) & \approx \Delta H_{\mathrm{m}}^{\mathrm{M}}\left(\mu\left(z_{\mathrm{c}}\right)\right) \\
& +\frac{\mathrm{d} \Delta H_{\mathrm{m}}^{\mathrm{M}}}{\mathrm{d} z}\left(\mu\left(z_{\mathrm{c}}\right)\right)\left[z_{\mathrm{c}}-\mu\left(z_{\mathrm{c}}\right)\right]
\end{aligned}
$$

with expectation value from Eq. (15) and using Eq. (12):

$$
\begin{aligned}
\mu\left(\Delta H_{\mathrm{m}}^{\mathrm{M}}\right) & =E\left[\Delta H_{\mathrm{m}}^{\mathrm{M}}\left(z_{\mathrm{c}}\right)\right]=\Delta H_{\mathrm{m}}^{\mathrm{M}}\left(\mu\left(z_{\mathrm{c}}\right)\right) \\
& =\frac{l}{2}\left[\frac{\tau_{\mathrm{c}}^{2}+3}{2\left(1+\tau_{\mathrm{c}}^{2}\right)}-\frac{\delta z^{2}}{6 l^{2}} \frac{\left(1-\tau_{\mathrm{c}}^{2}\right)}{\left(1+\tau_{\mathrm{c}}^{2}\right)}-1\right]
\end{aligned}
$$

with $E$ the expectation operator. The Rayleigh channel height assignment error variance follows from Eq. (16), using Eq. (12):

$$
\begin{aligned}
\sigma^{2}\left(\Delta H_{\mathrm{m}}^{\mathrm{M}}\right) & =E\left[\left(\Delta H_{\mathrm{m}}^{\mathrm{M}}\left(z_{\mathrm{c}}\right)-\mu\left(\Delta H_{\mathrm{m}}^{\mathrm{M}}\right)\right)^{2}\right] \\
& =\left[\frac{\mathrm{d} \Delta H_{\mathrm{m}}^{\mathrm{M}}}{\mathrm{d} z}\left(\mu\left(z_{\mathrm{c}}\right)\right)\right]^{2} E\left[\left(z_{\mathrm{c}}-\mu\left(z_{\mathrm{c}}\right)\right)^{2}\right] \\
& =\left[1-\left(\frac{\delta z}{l \sqrt{3}}\right)^{2}\right]\left[\frac{\left(\tau_{\mathrm{c}}^{2}-1\right)}{\left(\tau_{\mathrm{c}}^{2}+1\right)}\right]^{2} \frac{(l-\delta z)^{2}}{48} .
\end{aligned}
$$

From Eqs. (17) and (18), it is concluded that the Rayleigh channel height assignment error bias decreases with increasing layer thickness. In contrast with the Mie channel, the height assignment error variance depends on the cloud layer transmission due to the non-zero molecular signal contributions above and below the cloud layer.

As mentioned above, the Mie and Rayleigh channel COG location cannot be determined in the case of a particle layer inside the bin. As a consequence, the height assignment error cannot be estimated and thus not corrected, leaving an error in the Aeolus wind when assigning the observation to the centre of the measurement bin. To quantify the wind error a constant wind-shear with amplitude $\alpha\left(\mathrm{s}^{-1}\right)$ is assumed over the bin. From the linear relationship between wind velocity and altitude it follows that the wind error bias and standard deviation equal $\alpha \cdot \mu\left(\Delta H_{k}^{\mathrm{M}}\right)$ and $\alpha \cdot \sigma\left(\Delta H_{k}^{\mathrm{M}}\right)$ respectively, for $k=\{m, p\}$ and from Eqs. (13), (17) and (18). The wind error bias, standard deviation and root mean square error (RMSE) are displayed in Fig. 3. The latter equals the square root of the summed squares of bias and standard deviation.

We note that the interpretation of wind error standard deviation in the middle panel may be misleading. The location of cloud layers are randomly distributed when considering many different cloud scenes. But for a particular scene the vertical extent of the cloud layer will generally be constrained and may extend over long distances covering a number of Aeolus observations. For instance low-level stratus clouds with approximate constant cloud top height yield a constant wind error (thus systematic) in equal height bins that may extend over long distances along the Aeolus track. Such errors are known to be detrimental for NWP. Moreover, a large standard deviation indicates that height assignment and subsequent wind errors can be large for a particular cloud layer, i.e. of a given height, thickness and transmission. Hence, the RMSEs in the lower panels of Fig. 3 are a good proxy for expected biases in Aeolus winds for such individual cloud layers. The mean RMSE values from the bottom panels of Fig. 3 equal $1.66 \mathrm{~m} \mathrm{~s}^{-1}$ (Mie channel) and $1.34 \mathrm{~m} \mathrm{~s}^{-1}$ (Rayleigh channel) respectively, indicating that Rayleigh channel winds have smaller biases in the presence of cloud layers on average, when assuming equal occurrence of all possible cloud layer realizations from Fig. 3. We further elaborate on this below.

From Fig. 3 it is concluded that the bias for Rayleigh channel winds is largest for optically thick and geometrical thin particle layers. The bias for Mie channel winds is largest for optically thick and geometrical thick particle layers. For 

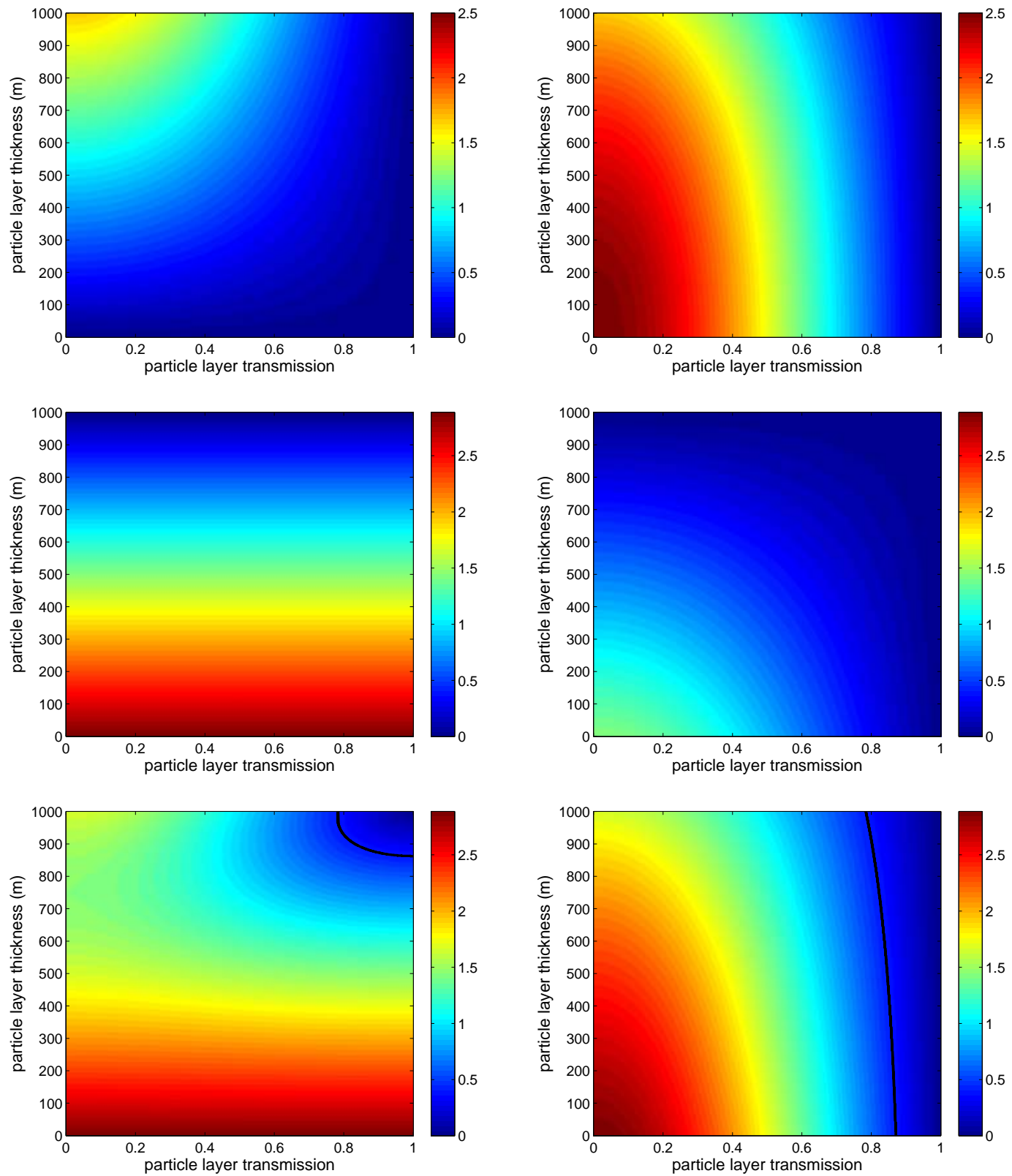

Figure 3. Mie (left column panels) and Rayleigh (right column panels) wind error bias ( $\mathrm{m} \mathrm{s}^{-1}$ ) (top row panels), standard deviation ( $\mathrm{m} \mathrm{s}^{-1}$ ) (middle row panels) and RMSE ( $\mathrm{m} \mathrm{s}^{-1}$ ) (bottom row panels) as a function of the one-way transmission of the particle layer, $\tau_{\mathrm{c}}$, and particle layer thickness $\delta z(\mathrm{~m})$. The measurement bin size $l$ is set at $1000 \mathrm{~m}$, the wind shear is taken as constant over the bin with a value of $0.01 \mathrm{~s}^{-1}$. The black solid lines in the bottom panels denote the Aeolus mission wind error bias requirement of $0.4 \mathrm{~m} \mathrm{~s}^{-1}$.

optically very thin clouds with a transmission value close to 1 , the Rayleigh channel signal is close to the particle-free atmosphere of the previous section. The height assignment error and wind velocity bias are close to zero, slightly underestimating the results found in the previous section due to the simplification of introducing the constant $w_{0}$. Particle layers that completely fill the measurement bin yield equal bias for the Mie and Rayleigh channel wind, see the panels in the top row of Fig. 3 for 1000 m layer thickness. This is in agreement with the equal weight function for the Mie and Rayleigh channel inside the particle layer. The bias for Rayleigh channel winds is maximized for thin but opaque clouds with transmission close to 0. From Eq. (17) the height assignment error equals $l / 4$ on average, giving a mean wind bias of $\alpha l / 4$, in agreement with a maximum wind bias of $\alpha l / 2$ for the cloud located at the top of the bin and a minimum bias of 0 for the cloud located at the bottom of the bin. For a typical wind shear in the free troposphere of $0.01 \mathrm{~s}^{-1}$ and 
an Aeolus bin size of $1 \mathrm{~km}$, the mean bias of Rayleigh channel winds for scenes of thin opaque clouds, such as e.g. PBL stratus, is thus $2.5 \mathrm{~m} \mathrm{~s}^{-1}$, i.e. much exceeding the mission requirement. The height assignment error standard deviation equals $\sqrt{l^{2} / 48}=144 \mathrm{~m}$ from Eq. (18) yielding a large wind error standard deviation of $1.43 \mathrm{~m} \mathrm{~s}^{-1}$. These results motivate the classification procedure implemented in the L2Bp to select measurements that are free of particles before integrating the measurements to observation level. The black solid lines in the bottom panels of Fig. 3 mark the Aeolus mission requirement of $0.4 \mathrm{~m} \mathrm{~s}^{-1}$ for the wind error bias. We argued above that the RMSE is a good measure for expected wind biases due to cloud layers. Mie channel winds fulfil the Aeolus requirement for particle layers with one-way transmission values above 0.75 and thickness above $850 \mathrm{~m}$. For particle layers with one-way transmission exceeding 0.8 Rayleigh winds fulfil the mission requirement, independent of the layer thickness. Somewhat smaller transmission values are allowed for geometrically thicker layers. These numbers are based on $0.01 \mathrm{~s}^{-1}$ wind shear and a $1 \mathrm{~km}$ measurement bin. Equations (13), (17) and (18) may be used for other parameter values. Table 1 provides an overview for typical atmospheric scenes.

From the results it is concluded that Mie channel winds show large height assignment errors and corresponding wind errors already for a typical shear value of $0.01 \mathrm{~s}^{-1}$. Rayleigh channel winds generally show much smaller errors, except for opaque clouds. These errors cannot be corrected, without additional information on the location and thickness of the cloud layer. Transmission of particle layers is available from the optical properties code under development as part of the L2Bp. From the two wind solutions, Rayleigh channel winds are generally preferred because the bias is largely independent of the (unknown) particle layer thickness. For particle layers with one-way transmission exceeding 0.8 Rayleigh channel winds are generally within the mission requirement, but care must be taken in dynamically active regions with large wind shears such as in the tropopause near the jet stream. For optically denser clouds, flagging the result as potentially affected by large biases is recommended. The usefulness of the Mie channel winds for NWP is questionable and needs further analysis.

In the subsequent sections we complement these theoretical results with real atmospheric winds and atmospheric backscatter derived from radiosonde data.

\section{Establishment of the radiosonde database}

Radiosondes measure wind speed and direction, temperature, pressure and relative humidity along the radiosonde path at high sampling rate. In this study we use data from the radiosonde from the Dutch Meteorological Institute, KNMI, located in De Bilt, the Netherlands $\left(52.1007^{\circ} \mathrm{N}, 5.1774^{\circ} \mathrm{E}\right.$, and $5 \mathrm{~m}$ a.s.l. - above sea level). KNMI operates a Vaisala
Table 1. Aeolus height assignment error $(\mathrm{m})$ and wind error $\left(\mathrm{m} \mathrm{s}^{-1}\right)$ (italic) RMSE for Mie (second column) and Rayleigh (third column) channel winds for typical atmospheric scenes with cloud and aerosol layers (first column). The numbers are based on Eqs. (13), (17) and (18), a $1000 \mathrm{~m}$ bin size and constant $0.01 \mathrm{~s}^{-1}$ wind shear over the bin.

\begin{tabular}{lcccc}
\hline & \multicolumn{2}{c}{ Mie channel } & \multicolumn{2}{c}{ Rayleigh channel } \\
\hline Stratus; $\tau=0 ; \delta z=100$ & 260 & 2.60 & 281 & 2.81 \\
Stratus; $\tau=0 ; \delta z=500$ & 153 & 1.53 & 239 & 2.39 \\
Cirrus; $\tau=0.8 ; \delta z=100$ & 260 & 2.60 & 62 & 0.62 \\
Cirrus; $\tau=0.8 ; \delta z=500$ & 145 & 1.45 & 53 & 0.53 \\
Aerosol; $\tau=0.99 ; \delta z=10$ & 286 & 2.86 & 3 & 0.03 \\
Aerosol; $\tau=0.5 ; \delta z=250$ & 218 & 2.18 & 160 & 1.60 \\
\hline
\end{tabular}

RS92 radiosonde that measures data every $2 \mathrm{~s}$. With an average ascent rate of about $5 \mathrm{~m} \mathrm{~s}^{-1}$, wind, temperature and humidity data are obtained at high vertical resolution of about $10 \mathrm{~m}$. WMO intercomparison test results show that the radiosonde RS92 is of high quality for all measurement parameters for in situ monitoring of upper air conditions (Houchi et al., 2010; Vaisala, 2011). During the entire study period, 1 January to 31 December 2007, radiosondes were launched two times a day (at 00:00 and 12:00 UTC) without any major interruption. Only the 12:00 UTC data were used in this study covering 309 valid launches of which $87.42 \%$ reached altitudes exceeding $20 \mathrm{~km}$. No data are available for the remaining 55 launches.

The observation site in De Bilt lacks instruments to provide a complete profile of aerosols and clouds. The available ceilometer measures cloud base heights only. Aerosol measurements are not performed over De Bilt. The UV lidar located nearby in Cabauw, further discussed Sect. 5, is mainly limited to the lower troposphere and not able to penetrate optically dense clouds. Observations from the Cloud-Aerosol Lidar with Orthogonal Polarization (CALIOP) instrument on the CALIPSO satellite (Winker, 2006) generally do not well coincide with wind observations from radiosondes, both in space and time (Houchi, 2013), thus limiting our data set.

To establish a database of high resolution winds and atmosphere optical properties, the method of Zhang et al. (2010) was adopted to detect clouds along the radiosonde path from measured temperature and relative humidity (RH) as discussed in Sect. 4.1. A parameterization for cloud and aerosol backscatter and extinction is discussed in Sects. 4.2 and 4.3 respectively, using measured $\mathrm{RH}$ along the radiosonde path.

\subsection{Detection of cloud vertical structure}

Various methods are available from literature to detect clouds along the radiosonde path, mainly by utilizing the humidity parameter (Poore et al., 1995; Chernykh and Eskridge, 1996; Wang and Rossow, 1995; Zhang et al., 2010, hereafter Zhang2010). The Zhang2010 method is applicable here since 

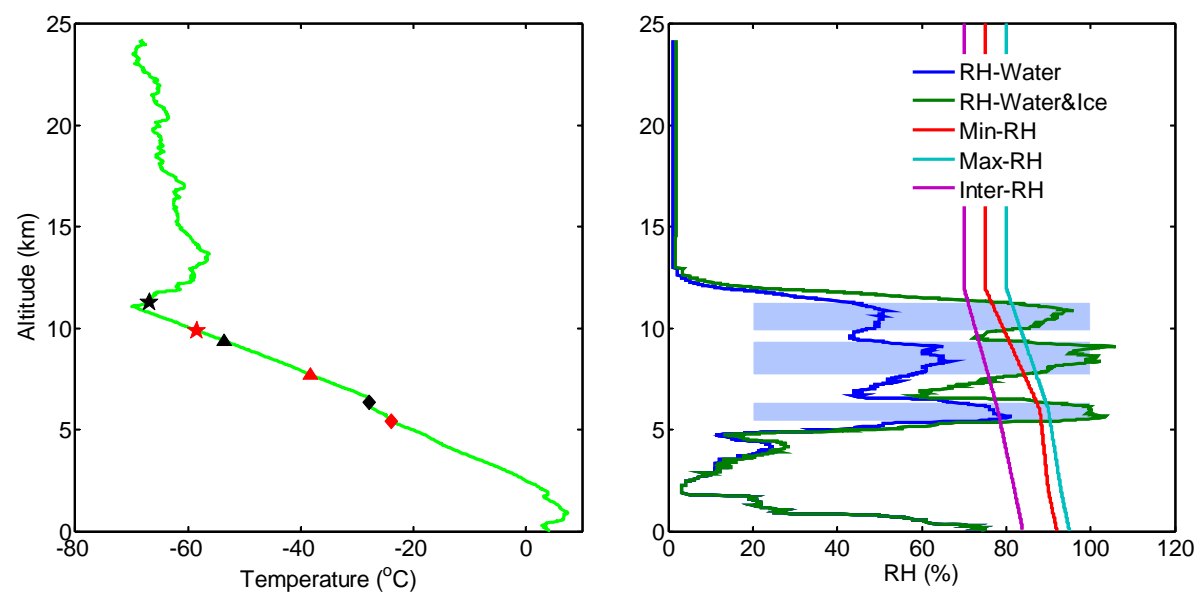

Figure 4. Typical example of cloud layer detection by the Zhang2010 method applied to a radiosonde launched in De Bilt on 25 December 2007 12:00 UTC. The left panel shows the temperature profile. Diamonds, triangles and asterisks correspond to the location of the lower, middle and upper cloud respectively with cloud base in red and cloud top in black. The right panel shows cloud layers detected by Zhang2010. The blue line represents measured $\mathrm{RH}$ with respect to water, the dark green line represents $\mathrm{RH}$ with respect to ice for levels with temperatures below $0{ }^{\circ} \mathrm{C}$, the red, purple and cyan lines represent min- $\mathrm{RH}$, inter-RH and max-RH thresholds as a function of altitude, respectively (see Table 1 of Zhang2010).

dedicated for application to RS92 radiosondes with high vertical resolution of about $10 \mathrm{~m}$, i.e. typical for the De Bilt radiosonde. For completeness, we summarize the main components of the Zhang2010 method. First, threshold profiles for $\mathrm{RH}$ are defined for cloud layer detection. These include (i) a profile of minimum $\mathrm{RH}$ (hereafter min-RH), (ii) a profile of minimum RH within the distance between two contiguous layers (hereafter inter-RH) and (iii) a profile of maximum RH (hereafter max-RH). Table 1 of Zhang2010 specifies the height-dependent threshold values for max-RH, min-RH and inter-RH that are also displayed in Fig. 4. Measured RH from RS92 needs recalculation for all levels with temperatures below $0{ }^{\circ} \mathrm{C}$ to get $\mathrm{RH}$ with respect to ice, which is needed in the Zhang2010 method. Here we use the relations proposed by Alduchov and Eskridge (1996) and the co-existence of liquid and ice is not considered in the Zhang2010 method.

The Zhang2010 algorithm is composed of the following steps: (1) the base of the lowest moist layer is detected as the level when RH exceeds the min- $\mathrm{RH}$ corresponding to this level (see Fig. 4); (2) the next levels above the base are checked and are temporarily treated as the same layer when $\mathrm{RH}$ exceeds the value of the corresponding min-RH; (3) the top of the moist layer is determined when $\mathrm{RH}$ decreases to below the corresponding min-RH value or RH still exceeds the corresponding min-RH value but the top of the profile is reached; (4) moist layers with bases lower than $120 \mathrm{~m}$ and thicknesses less than $400 \mathrm{~m}$ are discarded; (5) the detected moist layer is finally classified as a cloud layer only if the maximum value of $\mathrm{RH}$ within this layer is larger than the corresponding value for max-RH; (6) the base of cloud layers is set to $280 \mathrm{~m}$ a.g.l. (above ground level), and cloud layers are discarded if their tops are lower than $280 \mathrm{~m}$; (7) two contiguous layers are considered as a one-layer cloud if the distance between these two layers is less than $300 \mathrm{~m}$ or the minimum RH within this distance is more than the maximum inter-RH value within this distance; and (8) detected clouds are discarded for low-level clouds (below $2000 \mathrm{~m}$ ) with thickness less than $30.5 \mathrm{~m}$ and for clouds above $2000 \mathrm{~m}$ with thickness less than $61 \mathrm{~m}$.

Here we note that the Zhang2010 method described above was tuned for the Shouxian area during the rain season showing many days with fog layers near the surface. The climatological conditions for the Netherlands are quite different: there is no well defined rain season and fog is an infrequent event. We therefore discard points (4) and (6) of the procedure described above to allow for the detection of cloud layers near the surface. In addition for point (7), when combining two contiguous layers into one-layer cloud, the distance between these two layers is increased to $500 \mathrm{~m}$. This modification allows for validation with CloudSat/CALIPSO in Sect. 5.1.

Figure 4 shows a typical example of the application of the Zhang2010 method to radiosonde measured temperature (left panel) and humidity (right panel). The light blue regions in the right panel denote the locations of detected clouds with cloud base (top) height 5.4 (6.3) km, 7.7 (9.4) km and $9.9(11.3) \mathrm{km}$, respectively, marked by the symbols in the left panel. In the remainder of this study, we adopt the Zhang2010 method with the above modifications to detect the cloud vertical structure from radiosondes launched in De Bilt. Results are discussed in Sect. 5.1. 


\subsection{Cloud backscatter and extinction}

Cloud backscatter and extinction coefficients show a large variability of several orders of magnitude, depending on cloud type and laser wavelength. Table 2 is extracted from Vaughan et al. (1998) and has been used in various Aeolus studies. Local optical cloud heterogeneity is not simulated here, with which a clear source of wind error variability will be omitted eventually. On the other hand, quantifying backscatter/extinction variability inside water clouds has limited value for Aeolus assessment; a spaceborne UV lidar can hardly penetrate water clouds and observes the cloud top mainly. For ice clouds (e.g. cirrus) the situation is different. Figure 4 of Marseille et al. (2011) shows that a lidar signal can penetrate cirrus clouds. Also, these clouds may be thick and show large variability in convective regions. One could try and infer cloud ice content from radiosonde profiles to get a more variable and realistic vertical extinction profile for ice clouds using ECMWF profiles as (statistical) reference, but this is beyond the scope of this paper. On the other hand ice clouds over De Bilt are generally thin as shown in Fig. 8 of Sect. 5.1, suggesting that these clouds are the result of vertical mixing by wind shear rather than by convective activity. Optical variability is not the dominant source of atmosphere optical heterogeneity for thin clouds, supporting the use of the hypothetical clouds in Sect. 3.

Section 4.1 discussed the detection of cloud layers over De Bilt from radiosonde $\mathrm{RH}$ and temperature. The next step is to discriminate between water and ice clouds from radiosonde temperature. Liu et al. (2005) used MODIS data to quantify the observed frequency of cloud ice and water as a function of cloud temperature. They found that if the temperature at a cloud top is below $-17.16^{\circ} \mathrm{C}$, the probability of it being a water cloud is less than $20 \%$. From the cloud extinction coefficients in Table 2 and from CALIPSO experience, it is clear that the Aeolus laser beam will not be able to penetrate clouds with a substantial fraction of water droplets. On the other hand, clouds mainly composed of ice particles can be penetrated, depending on cloud thickness. We assume that clouds with temperature at cloud base below $-17.16^{\circ} \mathrm{C}$ can be classified as ice cloud, otherwise as a water cloud or mixed ice-water cloud. We choose to be conservative and assume that clouds containing any water cannot be penetrated by Aeolus.

\subsection{Parameterization of aerosol backscatter and extinction}

The previous sections discuss the detection of cloud extinction and backscatter layers over De Bilt. For a complete optical profile also aerosol backscatter and extinction over De Bilt are required. Here, we adopt a climatological aerosol backscatter profile at $355 \mathrm{~nm}$ that is adapted based on the known relationship between $\mathrm{RH}$ and the lidar backscatter coefficient. This has the advantage of having a perfect match
Table 2. Typical values of backscatter (second column) and extinction (third column) for various cloud types (first column) in the UV, visible and near-infrared part of the electromagnetic spectrum. The backscatter and extinction values are extracted from Vaughan et al. (1998). FW cumulus means fair weather cumulus, PSC means polar stratospheric cloud.

\begin{tabular}{lccl}
\hline Cloud type & $\begin{array}{c}\beta_{\mathrm{C}} \\
\left(\mathrm{m}^{-1} \mathrm{sr}^{-1}\right)\end{array}$ & $\begin{array}{c}\alpha_{\mathrm{C}} \\
\left(\mathrm{m}^{-1}\right)\end{array}$ & $\begin{array}{l}\text { Altitude range } \\
(\mathrm{km})\end{array}$ \\
\hline FW cumulus & $6.0 \times 10^{-4}$ & $1.2 \times 10^{-2}$ & $2-4$ \\
Stratus & $5.0 \times 10^{-3}$ & $9.0 \times 10^{-2}$ & $0.2-2$ \\
Alto-stratus & $1.0 \times 10^{-3}$ & $1.8 \times 10^{-2}$ & $2-6$ \\
Cumulonimbus & $1.0 \times 10^{-2}$ & $1.8 \times 10^{-1}$ & $2-16$ \\
Cirrus & $1.4 \times 10^{-5}$ & $2.0 \times 10^{-4}$ & $5-16$ \\
PSC & $3.0 \times 10^{-7}$ & $6.0 \times 10^{-6}$ & $16-30$ \\
\hline
\end{tabular}

of high resolution winds and atmospheric backscatter along each radiosonde path, a substantial part of the Holy Grail for testing Aeolus performance in heterogeneous atmospheric conditions. The realism of the resulting backscatter profiles is discussed in Sect. 5.2.

There are numerous choices for selecting a climatological aerosol backscatter profile, e.g. obtained from ground and flight campaigns or from space missions. Marseille et al. (2011) show climatologies from 1989 airborne campaigns, the 1994 LITE space shuttle experiment and a 2007 subset from CALIPSO, which were characterized as relatively clean, dirty and "in-between" periods, see their Fig. 7. We selected the aerosol backscatter climatology derived from lidar flight campaigns over the northern and southern Atlantic in 1989 (Vaughan, 1998), which has been used in many Aeolus studies and denoted the reference model atmosphere (RMA). The RMA median profile, denoted $\beta_{\mathrm{A}}^{\text {clim }}(z)$ $\left(\mathrm{m}^{-1} \mathrm{sr}^{-1}\right)$ in what follows, is smooth and shows a strong decrease of aerosol density from the surface up to $5 \mathrm{~km}$ altitude, followed by a less strong decrease in the range $5-15 \mathrm{~km}$, followed by a strong drop above $15 \mathrm{~km}$.

To simulate aerosol backscatter over De Bilt, denoted $\beta_{\mathrm{A}}(z)\left(\mathrm{m}^{-1} \mathrm{sr}^{-1}\right)$, we adapt the climatological profile through an aerosol scattering growth factor $f_{\text {scatt }}$ as follows, see e.g. (Rogers et al., 2006; Gasso et al., 2000):

$\beta_{\mathrm{A}}(z)=\beta_{\mathrm{A}}^{\mathrm{clim}}(z) \cdot f_{\mathrm{scatt}}(\mathrm{RH}(z))$

$f_{\text {scatt }}(\mathrm{RH}(z))=\left[(1-\mathrm{RH}(z) / 100) /\left(1-\mathrm{RH}_{\mathrm{ref}} / 100\right)\right]^{-0.5922}$

using a $30 \%$ reference value for $\mathrm{RH}_{\text {ref. }}$. The scattering growth factor is a function of RH which is obtained from the De Bilt radiosonde. Finally, aerosol extinction $\left(\mathrm{m}^{-1}\right)$ is needed to estimate the laser beam transmission through the atmosphere. Many studies use a linear relationship between the aerosol backscatter and extinction coefficients (e.g. Evans, 1988; Spinhirne et al., 1997; Liu et al., 2002; Marseille et al., 2011): 
$\alpha_{\mathrm{A}}=S \cdot \beta_{\mathrm{A}}$

with $\alpha_{\mathrm{A}}$ the aerosol extinction coefficient $\left(\mathrm{m}^{-1}\right), \beta_{\mathrm{A}}$ the aerosol backscatter coefficient $\left(\mathrm{m}^{-1} \mathrm{sr}^{-1}\right)$, and $S$ the extinction-to-backscatter ratio (sr) (also called the lidar ratio). Values for $S$ vary over a large range depending on the wavelength of the incident light, the aerosol refractive index, and the aerosol size distribution (Ackermann, 1998). Moreover, these aerosol characteristics change with the ambient RH. Ackermann (1998) proposed a parameterization of the lidar ratio, $S(\mathrm{RH})$, as a power series expansion of atmospheric RH:

$S(\mathrm{RH}) \approx \sum_{j=1}^{J} a_{j}(\mathrm{RH})^{j-1}$

with $a_{j}$ parameters that depend on laser wavelength and aerosol type. De Bilt is close to the coastal region but given the location of the four largest cities in the Netherlands close to the coast also human activity is concentrated west of De Bilt. The prevailing westerly winds over the Netherlands transport a mixture of marine and urban (also denoted pollution or continental) aerosols over De Bilt. Lidar measurements from the Cabauw site, further discussed in Sect. 5.2, identified urban aerosol as the dominant aerosol type over De Bilt. The corresponding parameters in the series expansion, Eq. (22), are obtained from Table 3 of Ackermann (1998) for continental aerosol. From Eq. (21) we get for the estimated aerosol extinction coefficient:

$\alpha_{\mathrm{A}}(z)=S(\mathrm{RH}(z)) \cdot \beta_{\mathrm{A}}(z)$

with $\beta_{\mathrm{A}}(z)$ from Eq. (19) and $S(\mathrm{RH}(z))$ from Eq. (22). Figure 5 shows a modest increase of the growth factor from 1 to 2 with increasing RH up to $80 \%$ then increasing fast to a maximum value of 6 for $\mathrm{RH}$ values above $80 \%$. This is explained by the swelling tendency of the aerosol particles for RH values exceeding the deliquescent point (Onasch et al., 1999). The lidar ratio grows from 42.5 to 70 (sr) for RH increasing from 0 to $100 \%$ with an uncertainty range between $\pm 1 \%$ and $\pm 14 \%$ at $355 \mathrm{~nm}$ wavelength (Ackermann, 1998).

\section{Validation of the radiosonde database}

The radiosonde-based cloud detection method, discussed in Sect. 4.1, has been applied to 1 year of radiosonde data measured at De Bilt in 2007. Statistics of detected cloud layers are presented in Sect. 5.1 followed by an extension of the validation in Zhang2010 for the De Bilt region. The aerosol backscatter and extinction parameterization discussed in Sect. 4.3 is validated against UV lidar data measured from the Cabauw observation site, located about $35 \mathrm{~km}$ from De Bilt, in Sect. 5.2.

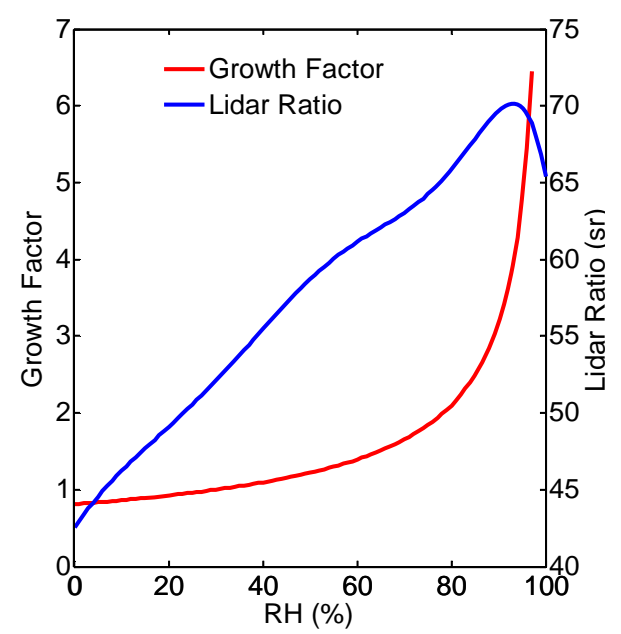

Figure 5. Simulations of the growth factor (red), Eq. (20), and lidar ratio (sr) (blue), Eq. (22), as a function of RH.

\subsection{Analysis and validation of radiosonde cloud detection}

In Sect. 3 it was shown that the thickness of a particle layer and its location relative to the Aeolus bin are important contributors to the Aeolus wind error. We found a total of 407 cloud layers over De Bilt for the 2007 period that were classified into four types, similar as in the literature (Poore et al., 1995; Lazarus et al., 2000; Zhang et al., 2010): (1) low clouds with bases below $2 \mathrm{~km}$ and thicknesses less than $6 \mathrm{~km}$; (2) middle clouds with bases ranging from 2 to $5 \mathrm{~km}$; (3) high clouds with bases above $5 \mathrm{~km}$; and (4) deep convective clouds with bases below $2 \mathrm{~km}$ and thicknesses larger than $6 \mathrm{~km}$. The relative occurrence of these four types is $44,22,31$ and $3 \%$, respectively. The mean location and thicknesses of these four cloud types are shown in Fig. 6 . The mean thickness of low, middle and high clouds does not vary a lot, except for deep convective clouds, and is close to the Aeolus bin size of typically $1 \mathrm{~km}$ in the free troposphere. However, the cloud thickness may vary substantially from case to case which becomes apparent from Fig. 7 that classifies scenes of multi-layered clouds.

The location and thicknesses of single- and multi-layered clouds are shown in Fig. 7. The number of one-, two-, threeand four-layer clouds are 108, 73, 32 and 13, respectively. From Figs. 7 and 8 it is already clear that the thickness of many clouds is smaller than the Aeolus bin size of typically $1 \mathrm{~km}$ in the free-troposphere. Cloud layers smaller than $1 \mathrm{~km}$ will generally affect the wind in a single Aeolus bin, but depending on the cloud top height location an additional bin may be affected. Whether clouds will also affect underlying bins depends on the cloud optical thickness; cirrus clouds are generally, at least partly, transparent. Cirrus clouds over De Bilt are generally thin. From Fig. 8 about $25 \%$ has thicknesses below $300 \mathrm{~m}$, and about $60 \%$ below $1 \mathrm{~km}$. These 


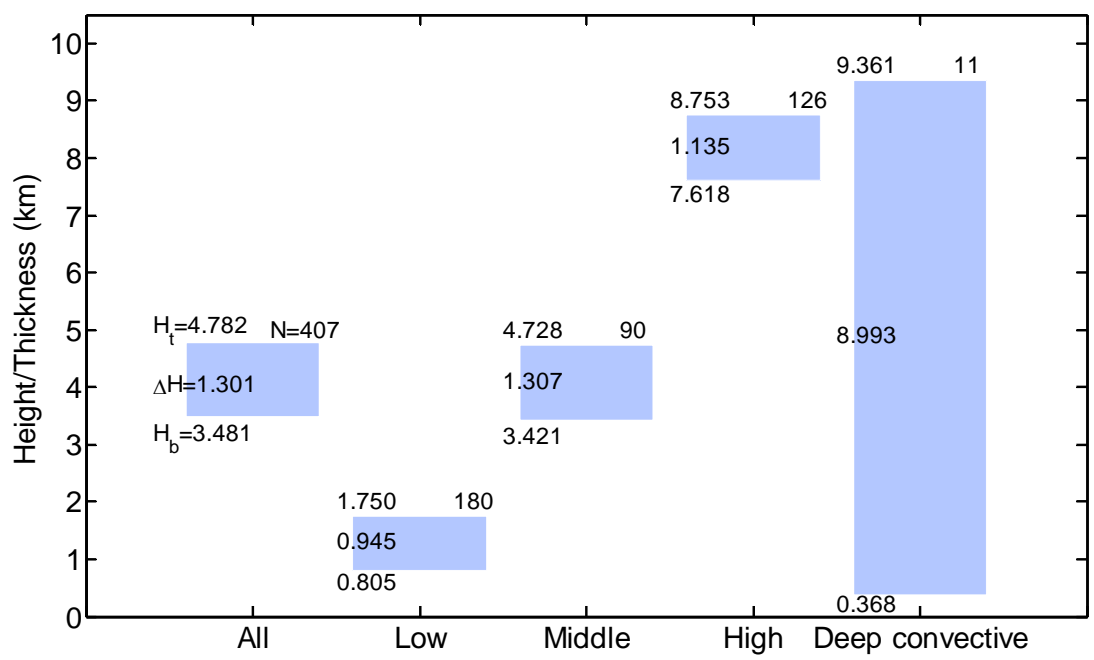

Figure 6. Mean location and thickness of all, low, middle, high and deep convective clouds. $H_{\mathrm{b}}, H_{\mathrm{t}}$ and $\Delta H$ (units in km) are the mean cloud base height, mean cloud top height and mean cloud thickness based on $N=407$ realizations.

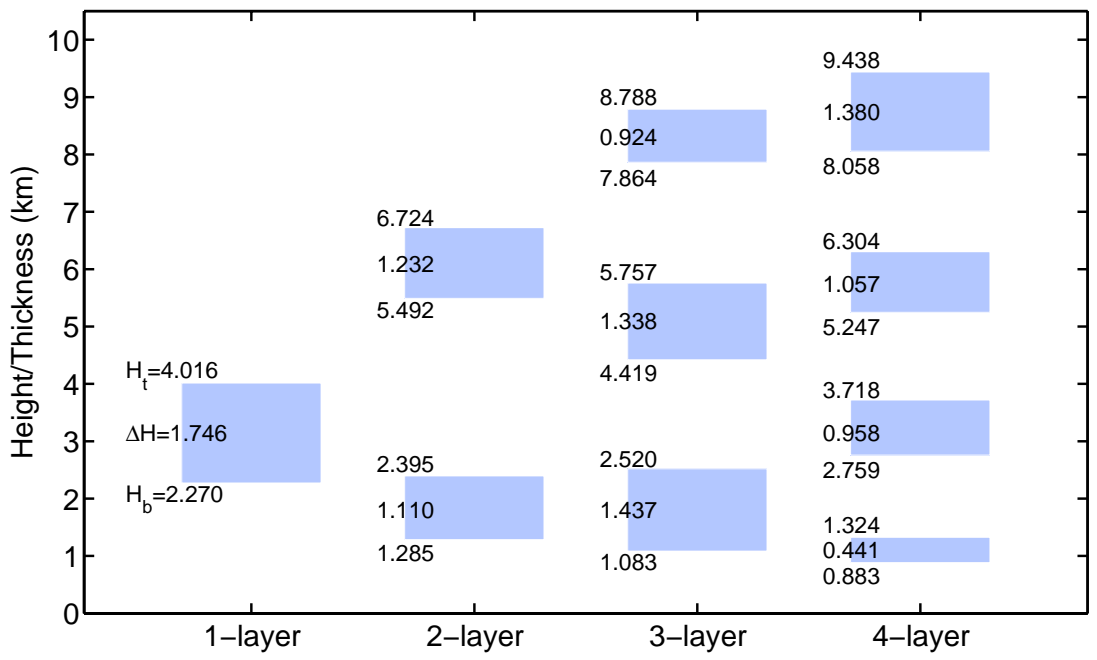

Figure 7. Location and thickness of single- and multi-layered clouds. $H_{\mathrm{b}}$ and $H_{\mathrm{t}}$ and $\Delta H$ (units in $\mathrm{km}$ ) are the mean cloud base height, mean cloud top height and mean cloud thickness for layered clouds, respectively.

numbers support the statement in Sect. 4.2 that cirrus clouds over De Bilt are most probably the result of vertical mixing by wind shear rather than by convective processes which generally produce thicker clouds with more optical variability. Of course, horizontal optical heterogeneity will much affect signal levels below the cloud layer.

The Zhang2010 method has been validated thoroughly in Zhang et al. (2010) with a focus on the Shouxian area during the rain season. The validation of the Zhang2010 method for different climatological conditions is beyond the scope of this paper. Yet, as an extension of Zhang2010, some additional validation was performed for the region near De Bilt, of which the most significant results are presented below.

First, cloud layer location parameters retrieved from radiosondes were compared with those obtained from the polar orbiting CloudSat and CALIPSO satellites. CloudSat carries a nadir-looking millimetre-wavelength Cloud Profiling Radar (CPR) that is operated at $94 \mathrm{GHz}$ to measure the power backscattered by clouds as a function of distance from the radar with vertical resolution of $240 \mathrm{~m}$ (Mace et al., 2007). CALIPSO carries the two-wavelength (532 and $1064 \mathrm{~nm}$ ) Cloud-Aerosol Lidar with Orthogonal Polarization (CALIOP) to measure atmosphere backscattered signals optimized for aerosol and cloud profiling with fundamental vertical and horizontal sampling resolutions of 30 and $333 \mathrm{~m}$, respectively (Winker, 2006). With the ability of the CPR to probe optically thick large-particle layers and CALIOP to sense optically thin cloud layers and aerosol, the two complementing instruments have the potential of providing a 


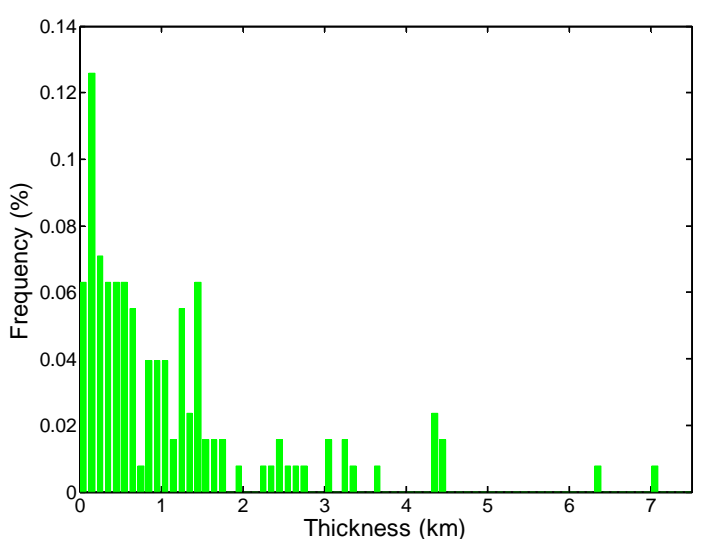

Figure 8. Occurrence of layer thickness $(\mathrm{km})$ for 127 ice clouds detected over De Bilt in 2007. The bin size is $100 \mathrm{~m}$.

complete picture of the presence of cloud and aerosol along the A-train track.

The mean cloud base and top height of cloud layers (denoted mean cloud base and mean cloud top in the title of the panels of Fig. 9) and the mean cloud top height of the uppermost cloud layer (denoted upper cloud top) as obtained from radiosondes were compared with those from the CloudSat/CALIPSO level-2 product (available from http: //www.cloudsat.cira.colostate.edu/). Criteria for observation matching in time and space are: the observation time difference is less than one hour and the distance less than $40 \mathrm{~km}$. For the 1 year 2007 period only 20 samples fulfilled these criteria near 12:00 UTC from which 16 contained clouds. The remaining four samples showed no clouds in both data sets. Figure 9 shows large correlation values of $0.86,0.84$ and 0.93 for mean cloud base, mean cloud top and upper cloud top, respectively. These large values may be surprising, given the remaining mismatch in time and space and the fundamental differences of both data sets such as (i) $10 \mathrm{~m}$ vertical resolution for radiosonde versus $240 \mathrm{~m}$ for CloudSat/CALIPSO, i.e. the latter may fail to detect thin cloud layers and (ii) signals of CloudSat/CALIPSO may strongly attenuate thus hampering to penetrate dense water clouds and failure to detect accurately the cloud base or underlying cloud layers. It is further noted that the threshold values for cloud detection from radiosonde data (Table 1 of Zhang2010) may be good on average but not optimal for specific scenes. Also the drift of the radiosonde from its launch location has not been taken into account, which is typically $50 \mathrm{~km}$ (Houchi et al., 2010).

Besides validation against independent observations validation against the ECMWF model was performed for cloud cover. Cloud cover refers to the fraction of the sky covered by clouds and is a standard output product of the ECMWF model and available from their MARS (meteorological archiving system) archive. Non-zero cloud cover at a certain model level means that part of the model grid box is filled with cloud, i.e. a value of 0.3 means that $30 \%$ of the model grid box is filled with cloud. Here, the annual mean cloud cover over De Bilt for 2007 as obtained from radiosondes is compared against cloud cover from ECMWF interpolated to the De Bilt location. Annual mean cloud cover, $\overline{\mathrm{cc}}$, at radiosonde altitude $z_{\mathrm{R}}$ is obtained as follows:

1. If a cloud layer is detected at radiosonde level $i$ with altitude $z_{\mathrm{R}}(i)$ for radiosonde launch numbered $j$ then $\operatorname{cc}_{\mathrm{R}}\left(z_{\mathrm{R}}(i), j\right)=1$, otherwise $\operatorname{cc}_{\mathrm{R}}\left(z_{\mathrm{R}}(i), j\right)=0$.

2. Averaging the cloud cover for all $N$ radiosonde retrievals over the 1 year 2007 period yields the annual mean cloud cover for each radiosonde height level:

$$
\overline{\operatorname{cc}_{\mathrm{R}}}\left(z_{\mathrm{R}}(i)\right)=\frac{1}{N} \sum_{j=1}^{N} \operatorname{cc}_{\mathrm{R}}\left(z_{\mathrm{R}}(i), j\right) .
$$

Similarly, the annual mean ECMWF model cloud cover, $\overline{\mathrm{cc}}_{\mathrm{M}}\left(z_{\mathrm{M}}(k)\right)$, is obtained but only at model levels $k$ with altitude, $z_{\mathrm{M}}(k)$. For a fair intercomparison of $10 \mathrm{~m}$ radiosonde and ECMWF model cloud cover, the calculated mean radiosonde cloud cover is averaged over $M_{\mathrm{k}}$ radiosonde levels around model level $l$ :

$$
\begin{aligned}
\overline{\operatorname{cc}_{\mathrm{R}}}\left(z_{\mathrm{M}}(k)\right) & =\frac{1}{M_{\mathrm{k}}} \sum_{i=1}^{M_{\mathrm{k}}} \overline{\mathrm{cc}_{\mathrm{R}}}\left(z_{\mathrm{R}}(i)\right) \\
& =\frac{1}{N M_{\mathrm{k}}} \sum_{i=1}^{M_{\mathrm{k}}} \sum_{j=1}^{N} \operatorname{cc}_{\mathrm{R}}\left(z_{\mathrm{R}}(i), j\right) .
\end{aligned}
$$

This is done for all model levels $k$. Figure 10 shows a larger/smaller cloud coverage of the Zhang2010 method below/above $8 \mathrm{~km}$ relative to ECMWF. This result gives good confidence in the Zhang2010 method because it agrees with Houchi (2013) who showed an underestimate of ECMWF model cloud below $8 \mathrm{~km}$ and an overestimate above $8 \mathrm{~km}$ relative to the CALIPSO level- 2 product.

Finally, we mention that a thorough intercomparison between the Zhang2010 and the method from Wang and Rossow (1995) for the De Bilt radiosonde confirmed earlier conclusions from Zhang et al. (2010) of better results obtained from their method (not shown).

\subsection{Validation of aerosol backscatter and extinction}

The parameterization for aerosol backscatter and extinction, discussed in Sect. 4.3, is validated in this section against ground-based observations from the commercial UV lidar (ALS-300 system manufactured by Leosphere) operated by KNMI at the Cabauw observation site $\left(51.97^{\circ} \mathrm{N}, 4.926^{\circ} \mathrm{E}\right)$ located about $30 \mathrm{~km}$ southwest of De Bilt. We focus on the vertical variability of aerosol density within Aeolus bins which may cause biases in Aeolus winds as discussed in Sect. 3. The UV lidar is a compact vertically pointing (nonscanning) lidar with orthogonal polarization and using a frequency tripled Nd:YAG laser transmitting $12 \mathrm{~mJ}$ pulses of 

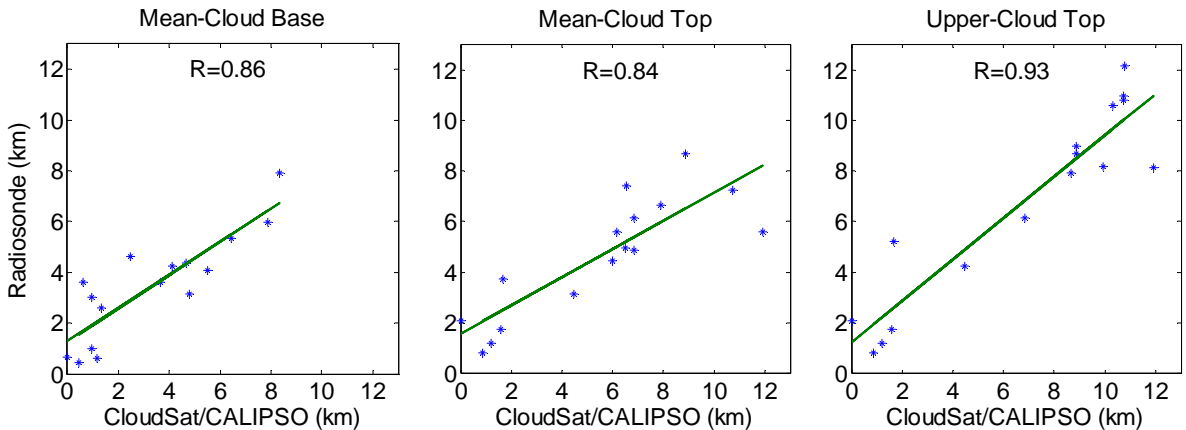

Figure 9. Comparison of mean cloud base (left panel), mean cloud top (middle panel) and upper cloud top (right panel) between CloudSat/CALIPSO and radiosonde data processed by Zhang2010, based on 20 collocations found in 2007 of which 16 contained clouds. $R$ denotes the correlation value between both data sets.

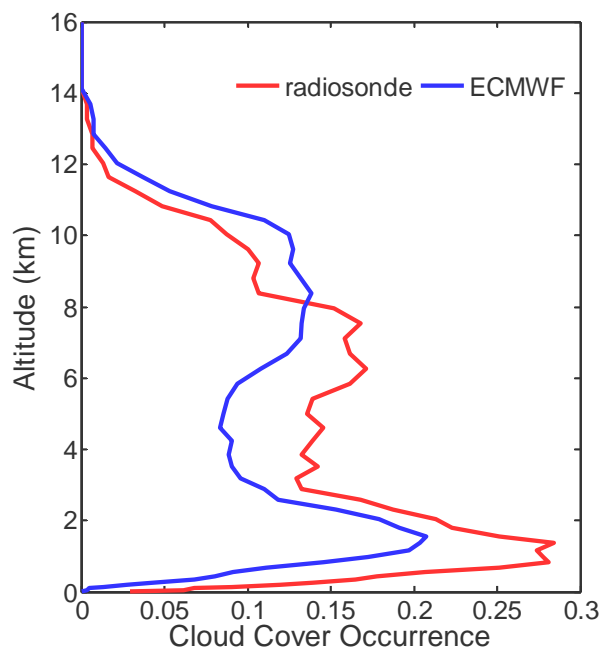

Figure 10. Annual mean cloud cover over De Bilt for the 1-year period 2007 as obtained from the Zhang2010 method applied to radiosonde data (red) and from ECMWF cloud cover interpolated to De Bilt (blue). The correlation coefficient between the curves equals 0.91 .

$355 \mathrm{~nm}$ wavelength at $20 \mathrm{~Hz}$. The detection range is about 20 $\mathrm{km}$. The UV lidar is operational since 5 July 2007. The UV lidar product includes backscatter profiles (both perpendicular and parallel) for $30 \mathrm{~s}$ accumulation intervals with a vertical resolution of $15 \mathrm{~m}$. To improve the signal-to-noise of the UV lidar data, lidar profiles were averaged over $30 \mathrm{~min}$ intervals centred at 12:00 UTC before comparing with 12:00 UTC radiosonde profiles. A disadvantage of a ground-based lidar is blocking of the signal by low-level clouds obscuring the atmosphere aloft. No aerosol information can be retrieved above clouds. Hence, for the intercomparison only cloudfree scenes were considered in the period 5 July 2007 until the end of 2007. A total of 48 cloud-free scenes were found. The aerosol backscatter estimates were derived from the lidar attenuated backscatter signals using a Klett-Fernald approach (Klett, 1985; Fernald, 1984) with an assumed $S$ ratio of $50 \mathrm{sr}$ which is appropriate for urban aerosols (Müller et al, 2007). Using an $S$ value appropriate for maritime aerosols (20 sr) (Groß et al., 2011) leads to retrieved backscatter values which are about $40-80 \%$ higher at $0.5 \mathrm{~km}$ and $20-40 \%$ higher at $1.0 \mathrm{~km}$ with diminishing differences above this height.

Figure 11 shows that both the average aerosol backscatter from radiosondes and the UV lidar show a constant backscatter from the surface up to $500 \mathrm{~m}$ ( $800 \mathrm{~m}$ for the UV lidar) then dropping by an order of magnitude (slightly less for the UV lidar) for altitudes up to $2 \mathrm{~km}$. Near the surface the median aerosol backscatter from the UV lidar is about a factor 4 smaller than from the radiosonde. Here we note that the magnitude of the radiosonde aerosol backscatter is strongly related to the climatological RMA profile that was obtained from flight campaigns over the northern and southern Atlantic in 1989 as discussed in Sect. 4.3 and thus not expected to be representative for De Bilt in 2007. The comparison with the UV lidar values is also impacted by the fact that the lidar overlap function is incomplete below $300 \mathrm{~m}$. Based on the fitting of an overlap model in the case of low aerosol loading conditions, it was determined that the lidar overlap was more than $95 \%$ complete at $300 \mathrm{~m}$. An empirical overlap correction from Guerrero-Rascado et al. (2010) has been applied to the lidar data to extend the range of valid data to $100 \mathrm{~m}$. The larger spread of the quartile profiles for the UV lidar indicates an underestimation of the variability of aerosol backscatter as derived from radiosondes. To further elaborate on this we consider a typical bin size for the Aeolus Mie channel in the boundary layer of $250 \mathrm{~m}$. The difference between the maximum and minimum backscatter value within the vertical bin is a measure of backscatter variability, $\delta \beta$, and calculated, for $250 \mathrm{~m}$ bins, from

$\delta \beta_{i}=\left[\max \left(\beta_{i}\right)-\min \left(\beta_{i}\right)\right] / 250$

for range gate intervals $[250 \times(i-1), 250 \times i] \mathrm{m}$, $i=1, \ldots, 8$, where $\max \left(\beta_{i}\right)$ and $\min \left(\beta_{i}\right)$ are the maximum and minimum backscatter value in bin $i$ respectively. 


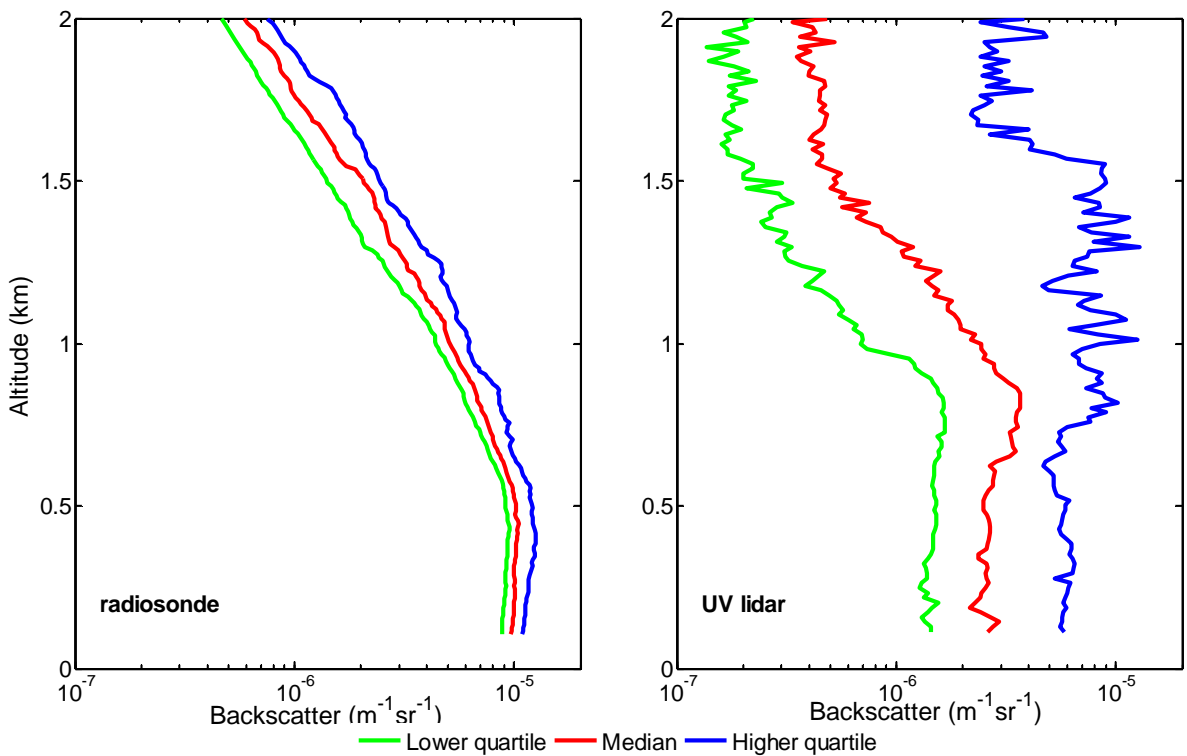

Figure 11. Aerosol backscatter coefficient $\left(\mathrm{m}^{-1} \mathrm{sr}^{-1}\right)$ statistics at $355 \mathrm{~nm}$ wavelength as obtained from radiosondes (left panel) and the UV lidar (right panel). Red/green/blue lines denote the median/lower quartile/higher quartile percentiles, respectively.
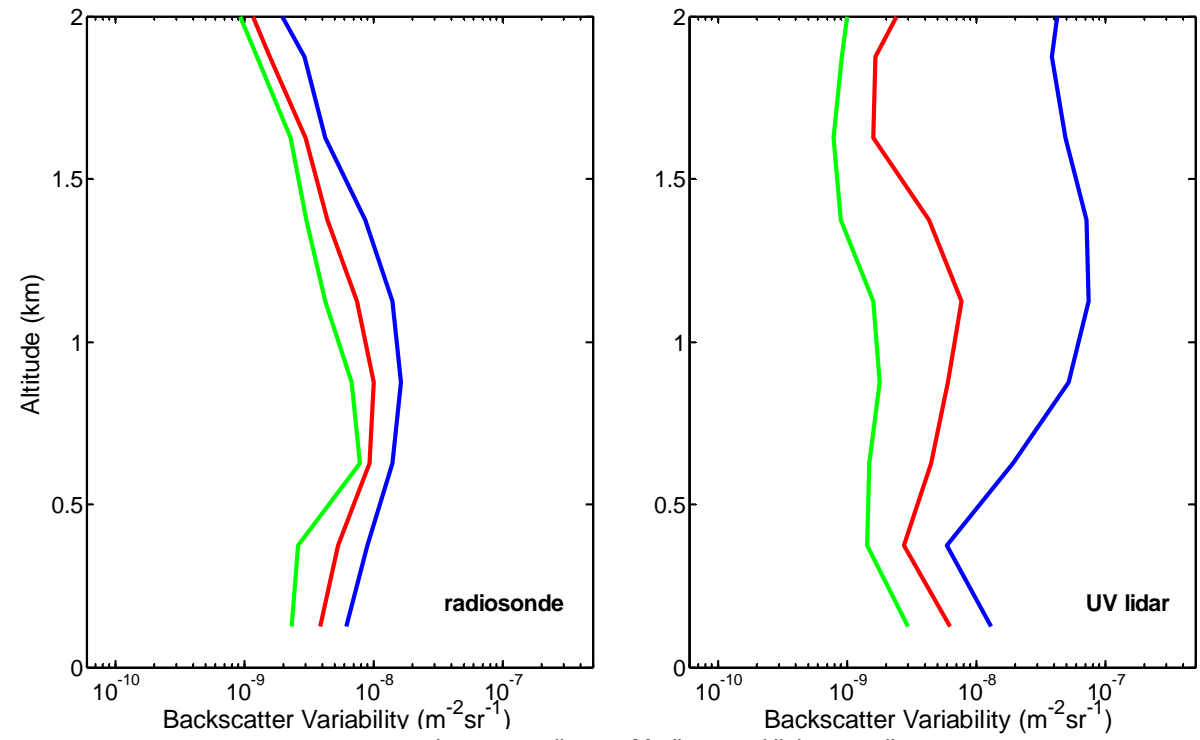

Figure 12. As Fig. 11 but now for the aerosol backscatter coefficient variability $\left(\mathrm{m}^{-2} \mathrm{sr}^{-1}\right)$.

Similar to Fig. 11, the aerosol backscatter variability shows an increase from the surface in the lower part of the boundary layer for both the radiosonde and UV lidar in Fig. 12 and then decreasing for altitudes up to $2 \mathrm{~km}$. The radiosonde median profile is generally larger than from the UV lidar suggesting larger variability within $250 \mathrm{~m}$ bins from the radiosonde aerosol backscatter. However, the substantially lower/higher decile curves for the UV lidar suggest that scenes observed by the lidar are more heterogeneous than those simulated for the radiosonde. Random instrument noise is a small factor here given the $30 \mathrm{~min}$ averaging of lidar attenuated backscatter before processing.

In conclusion, the mean aerosol backscatter variability simulated from radiosonde observations is representative for real atmospheric scenes as measured by the UV lidar with an overestimate (on average) in the lowest $700 \mathrm{~m}$ of the boundary layer. However, the lidar data show many cases with much larger backscatter variability than simulated by radiosondes. 

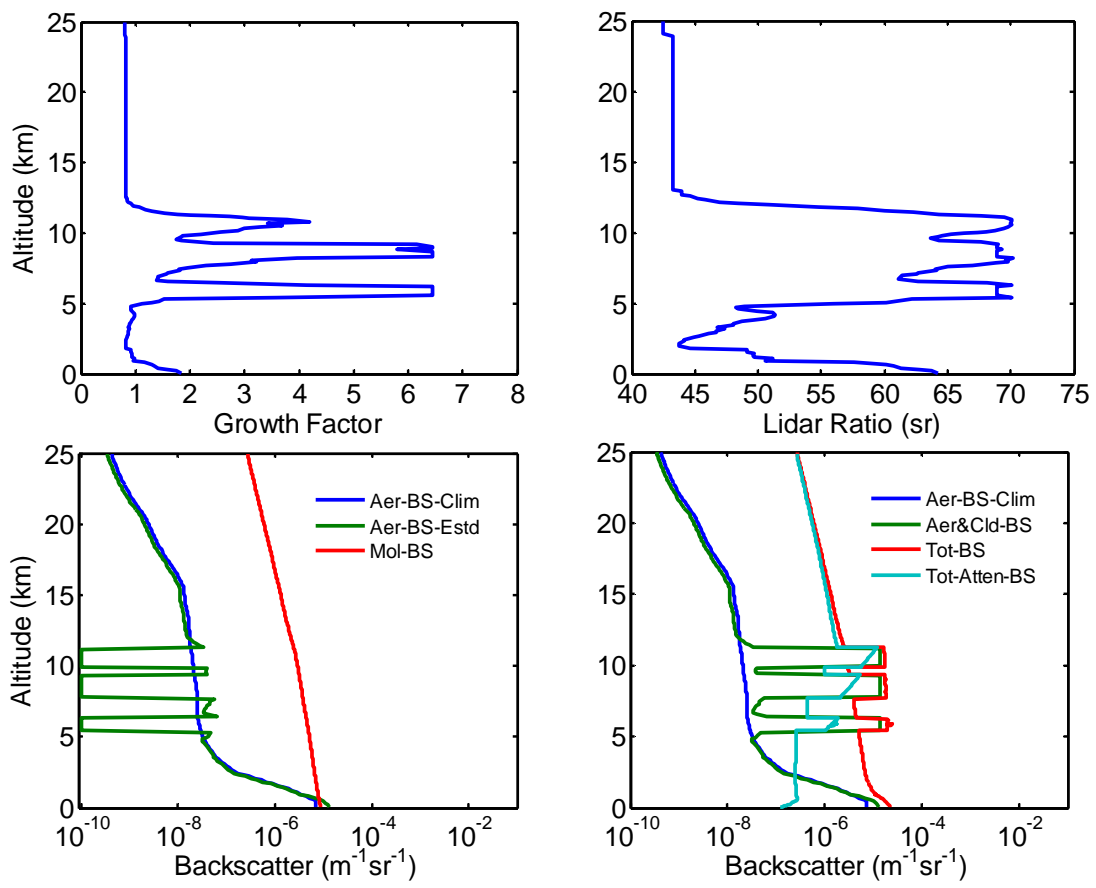

Figure 13. Aerosol growth factor (top left panel) and lidar ratio of aerosol (top right panel) obtained from the radiosonde data launched in De Bilt on 25 December 2007, 12:00 UTC. The parameterized aerosol backscatter in the bottom left panel (dark green) deviates from climatology (blue) and is set to zero for cloud presence. The red curve denotes molecular backscatter. The lower right panel shows total particle (aerosol plus cloud) backscatter $\left(\mathrm{m}^{-1} \mathrm{sr}^{-1}\right.$ ) (dark green), total (from molecules, aerosols and clouds) backscatter (red) and attenuated total backscatter (cyan).

\section{Application to the Aeolus mission}

It was stated in Sect. 1 that non-homogeneous atmospheric conditions within Aeolus observation bins cause errors in retrieved winds. In Sect. 3 an analytical evaluation provided typical equations to quantify Aeolus wind errors due to atmospheric heterogeneity. These equations are used in this section using the high vertical resolution $(10 \mathrm{~m})$ radiosonde database of collocated winds and atmosphere optical characterization at $355 \mathrm{~nm}$ (i.e. the Aeolus laser wavelength) derived and analysed in Sects. 4 and 5.

To estimate Aeolus biases for real atmospheric scenes, Eqs. (1) and (2) are applied to the radiosonde database. The database includes wind, temperature, pressure and $\mathrm{RH}$ at $10 \mathrm{~m}$ resolution and collocated aerosol and cloud backscatter and extinction as derived from the Zhang2010 method and parameterizations discussed in Sect. 4. The LIPAS tool (Marseille and Stoffelen, 2003) was used to calculate molecular backscatter and extinction from the radiosonde temperature and pressure profiles, using Rayleigh scattering laws. Figure 13 shows a typical example. The aerosol growth factor in the top left panel is applied to the climatological aerosol backscatter profile to define the aerosol backscatter profile in the bottom left panel, see also Eq. (19). Note that we discriminate between aerosol and cloud particles, meaning that at locations where clouds have been detected, we assume that aerosols were used as condensation nuclei to generate clouds and the aerosol density is set equal to zero. Aerosol extinction is next obtained using the lidar ratio in the top right corner (Eq. 21). Cloud locations are displayed in the right panel of Fig. 4. The temperatures at the cloud bases are below $-20^{\circ} \mathrm{C}$, so all three clouds are considered ice clouds and backscatter and extinction obtained from Table 2, assuming cirrus cloud type. Resulting cloud backscatter is displayed in the bottom right panel of Fig. 13 in addition to the total (from molecule, aerosol and cloud) atmospheric backscatter and attenuated total backscatter $w_{\mathrm{m}}(z)+w_{\mathrm{p}}(z)$ (see Eq. 10). The latter substantially decreases inside clouds.

First, the weight function and height assignment error of Rayleigh channel winds in a particle-free atmosphere were obtained from the discretized version of Eq. (2), using Eq. (7). The left panel of Fig. 14 shows that the analytical expressions Eqs. (3)-(7) overestimate (attenuated) molecular backscatter and best fit in the troposphere and with an overestimation in the stratosphere by almost a factor of 2 . The small band of percentiles show that molecular backscatter and extinction are relatively insensitive to temperature and pressure fluctuations at one specific location. The resulting height assignment error in the right panel of Fig. 14 is slightly larger than obtained from the analytical calculations in Sect. 3.1, i.e. about $10 \mathrm{~m}$ for a $2 \mathrm{~km}$ height bin in the stratosphere. The result is relatively insensitive to the actual atmospheric 

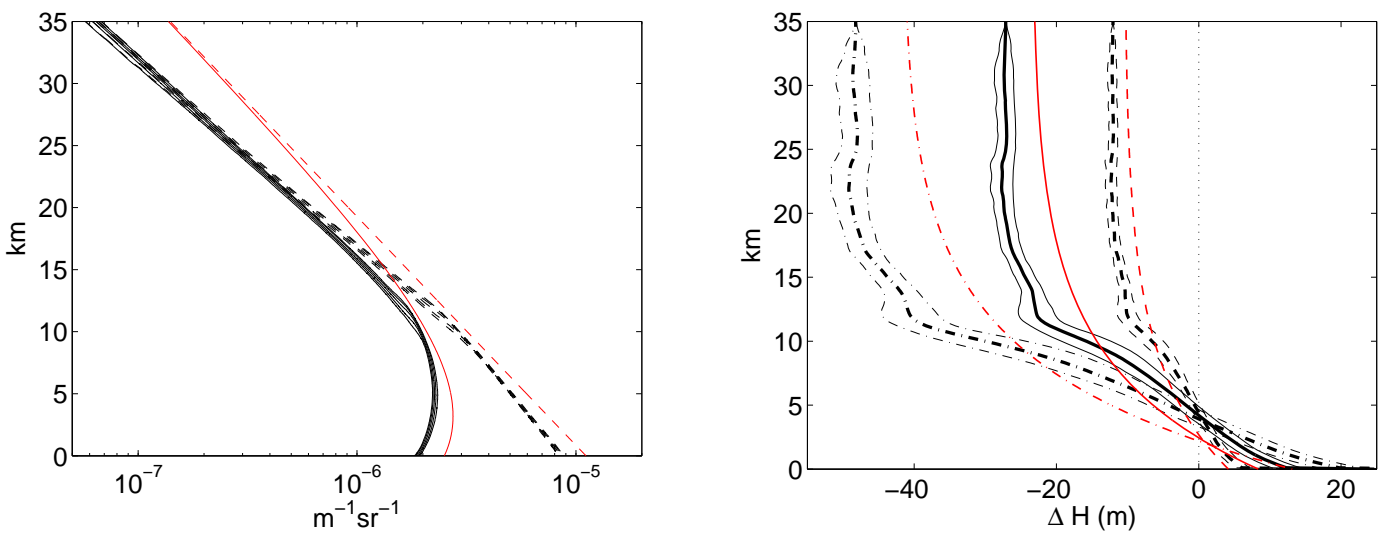

Figure 14. Statistics of (attenuated) molecular backscatter (left panel) and height assignment error $(\Delta H)$ of Rayleigh channel winds in particle-free atmospheric scenes (right panel) as obtained from temperature and pressure observations from 309 radiosondes launched at De Bilt covering the complete year 2007. The left panel shows 10th, 25th, 50th, 75th and 90th percentiles for molecular backscatter (black dashed) and attenuated backscatter (black solid). The corresponding analytical profiles (red) are identical to the left panel of Fig. 1. The right panel shows the mean $\Delta H$ (black, thick) and $\Delta H$ plus and minus the standard deviation for a measurement bin size of $1000 \mathrm{~m}$ (dashed), $1500 \mathrm{~m}$ (solid) and $2000 \mathrm{~m}$ (dash-dotted). The red curves are from the analytical evaluation and copied from Fig. 2. The dotted black line denotes zero $\Delta H$

temperature with deviations from the mean value in the order of only a couple of metres.

The L2Bp makes use of so-called auxiliary meteorological (AUXMET) data which include NWP model forecasts of temperature and pressure profiles at Aeolus observation locations. As an alternative, NWP centres running their own global model and the L2Bp may use their model output for AUXMET. Among others, AUXMET data will be used to correct for height assignment errors of Rayleigh channel winds in particle-free atmospheric bins, following the methodology described in Sect. 3.1 and above. This is part of the L2Bp currently under development.

The radiosonde database contains all ingredients to calculate Eqs. (1) and (10) and the Aeolus wind error profile $u_{k}^{\mathrm{M}}-u^{T}, k=\{\mathrm{p}, \mathrm{m}\}$, as a function of Aeolus bin size. The error profiles are calculated for each day of the year 2007 from which the wind error bias and standard deviation are calculated for each height bin. It is noted that the L2Bp includes a classification algorithm that decides on the presence of particles inside the measurement bin. The decision is based on an estimate of the scattering ratio from the Mie channel signal (Tan et al., 2008) that is defined as the ratio of total backscatter (from aerosol plus cloud plus molecules) and molecular backscatter. The value is always larger than 1 , when ignoring signal noise, and a threshold value of 1.2 has been selected as default value in the latest version of the L2Bp, but is adjustable. Bins with a scattering ratio exceeding the threshold value are assigned as particle bins, otherwise as particle-free bins. For consistency with the L2Bp the same procedure is applied to the processing of the radiosonde database: Mie winds are obtained only for bins with the scattering ratio exceeding the threshold value.
The Mie wind error statistics in the left panel of Fig. 15 show that both the wind error bias and standard deviation increase for increasing bin size, as expected since atmospheric variability increases with length scale. Near the surface $250 \mathrm{~m}$ Mie bins are foreseen for zero-wind calibration from surface returns. At higher altitudes, larger Mie bins are foreseen because of decreasing aerosol content with altitude, on average, and to enable Mie cloud and wind retrieval at altitudes in the upper troposphere and given that the total number of available vertical bins is limited to 24 . For $1000 \mathrm{~m} \mathrm{Mie}$ bins, the Mie wind error bias through atmospheric heterogeneity is smaller than the standard deviation, in agreement with Fig. 3 from the theoretical analysis. The standard deviation is between 1 and $1.5 \mathrm{~m} \mathrm{~s}^{-1}$ for most part of the free troposphere and lower stratosphere. These numbers are of similar magnitude as the Mie channel instrument noise error standard deviation of about $1 \mathrm{~m} \mathrm{~s}^{-1}$ (Marseille et al., 2013). However, for extended stratiform cloud layers, these errors may be horizontally and vertically correlated and not really random. In those cases biases of the size of the RMSE may occur, much exceeding the bias threshold of $0.4 \mathrm{~m} \mathrm{~s}^{-1}$. For $2000 \mathrm{~m}$ bin size the error standard deviation is about doubled. For $500 \mathrm{~m}$ bins the error standard deviation is between 0.5 and $1 \mathrm{~m} \mathrm{~s}^{-1}$. However, note that for $500 \mathrm{~m}$ bins the maximum altitude for Mie wind observations is chosen always below $12 \mathrm{~km}$, due to the limitation to 24 vertical bins.

Figure 16 zooms in on the lower part of the atmosphere and compares three different particle regimes. Wind is obtained from the radiosonde database. For a smooth distribution of particles, following the climatological RMA profile introduced in Sect. 4.3, the Mie wind error standard deviation is small: below $0.1 / 0.2 \mathrm{~m} \mathrm{~s}^{-1}$ for $250 / 500 \mathrm{~m}$ bins. For more realistic aerosol variability from the parameterization 

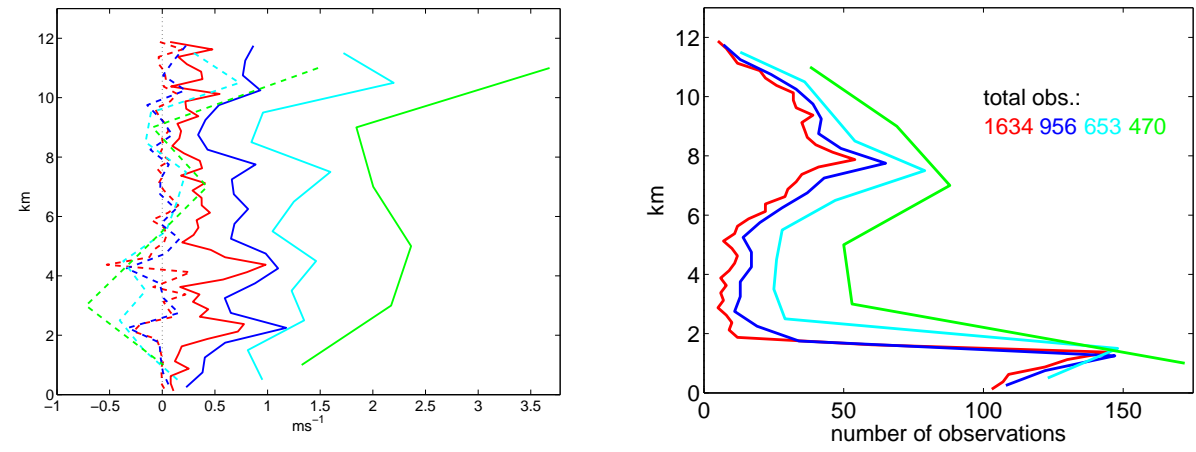

Figure 15. Aeolus Mie wind error statistics (left panel) and coverage (right panel) as a function of bin size: $250 \mathrm{~m}$ (red), $500 \mathrm{~m}$ (blue), $1000 \mathrm{~m}$ (cyan) and $2000 \mathrm{~m}$ (green). Dashed and solid lines in the left panel correspond to the error bias and standard deviation, respectively. The statistics are based on 309 radiosondes launched at 12:00 UTC in De Bilt in 2007. The total number of Mie winds as a function of bin size is given in the legend of the right panel.

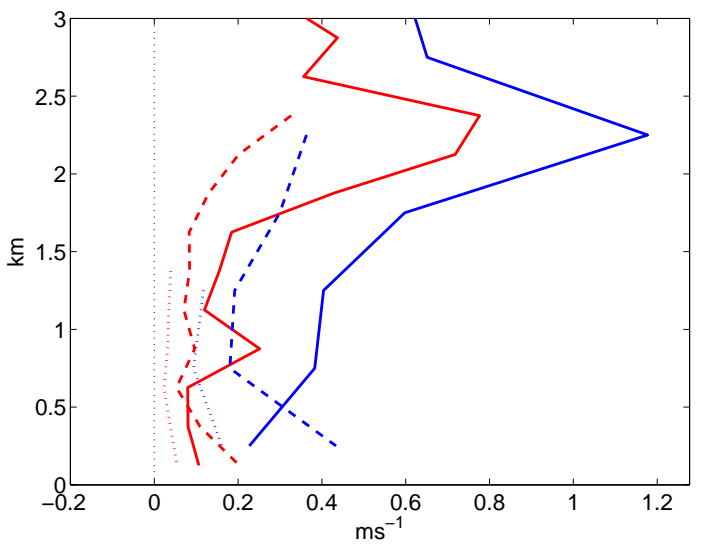

Figure 16. Mie wind error standard deviation for $250 \mathrm{~m}$ (red) and $500 \mathrm{~m}$ (blue) bin size for three different particle regimes: (i) a climatological smooth aerosol reference model atmosphere (dotted), no clouds, (ii) the parameterization of Eq. (19) (dashed), no clouds and (iii) from the radiosonde database, i.e. Eq. (19) for aerosol backscatter, including clouds (solid). The solid lines are identical to Fig. 15.

of Eq. (19), the Mie wind error standard deviation is $0.1-$ $0.2 / 0.2-0.4 \mathrm{~m} \mathrm{~s}^{-1}$ for $250 / 500 \mathrm{~m}$ bins. Because of increased aerosol density relative to the RMA, Mie winds are obtained up to $2.5 \mathrm{~km}$ as compared to $1.5 \mathrm{~km}$ for the RMA regime. Above these altitudes the aerosol density is too low for Mie wind retrieval. Finally, considering the complete particle distribution including clouds further substantially increases the error standard deviation of Mie winds. Note that additional errors due to horizontal variability (e.g. aerosol and cloud variability due to boundary layer eddies) are still ignored here.

It is concluded that Aeolus Mie wind quality is sensitive to the vertical heterogeneity of the atmosphere, in particular for scenes with cloud layers; Mie winds from cloud layers show large errors at all altitudes. The same is probably true for thick aerosol layers (for instance desert dust) and horizontal structures, although not explicitly studied here. These conclusions are well in line with the theoretical analysis of Sect. 3. In moderate aerosol regimes the corresponding Mie wind errors are much smaller than the instrument noise. Based on these conclusions it is recommended to separate Mie winds obtained from optically thin (moderate aerosol) and optically thick (cloud and dense aerosol) atmospheric layers. Discrimination between both regimes may be done from the available scattering ratio and/or the layer optical thickness. Calculation of the latter is not yet part of the L2Bp.

The data coverage in the right panel of Fig. 15 shows a strong peak around $1.5 \mathrm{~km}$ which corresponds to the average top of the boundary layer over De Bilt at 12:00 UTC. Below the PBL top Mie winds are obtained from both aerosol and cloud scattering. At higher altitudes, Mie winds are from cloud scattering only. The probability of encountering cloud increases for larger bin sizes. This explains the increasing number of observations with increasing bin size as a function of bin altitude in the right panel of Fig. 15. However, the total number of Mie winds decreases with increasing bin size, which is explained by noting that for instance a single $2000 \mathrm{~m}$ bin includes eight $250 \mathrm{~m}$ bins.

In Sect. 5.2 it was found that the mean aerosol backscatter variability in the radiosonde database well represents the real atmosphere as observed by the UV lidar, but the cases with larger backscatter variability (quartile) are underestimated by a factor of 5 above $500 \mathrm{~m}$ height. We conclude that the RMSE errors in the case of aerosol could be substantially larger.

Figure 17 shows the statistics for Rayleigh winds. Above $13 \mathrm{~km}$, no clouds were detected by the Zhang2010 method for the 2007 radiosondes over De Bilt and aerosol density is negligible. The non-zero error above $13 \mathrm{~km}$ is explained by the height assignment error of Rayleigh winds, see Fig. 14, resulting in an error standard deviation of a few tenths of a $\mathrm{m} \mathrm{s}^{-1}$, in agreement with the theoretical values found in Sect. 3.1. Below $13 \mathrm{~km}$, the Rayleigh wind error increases substantially (solid lines). Above the boundary layer this is 

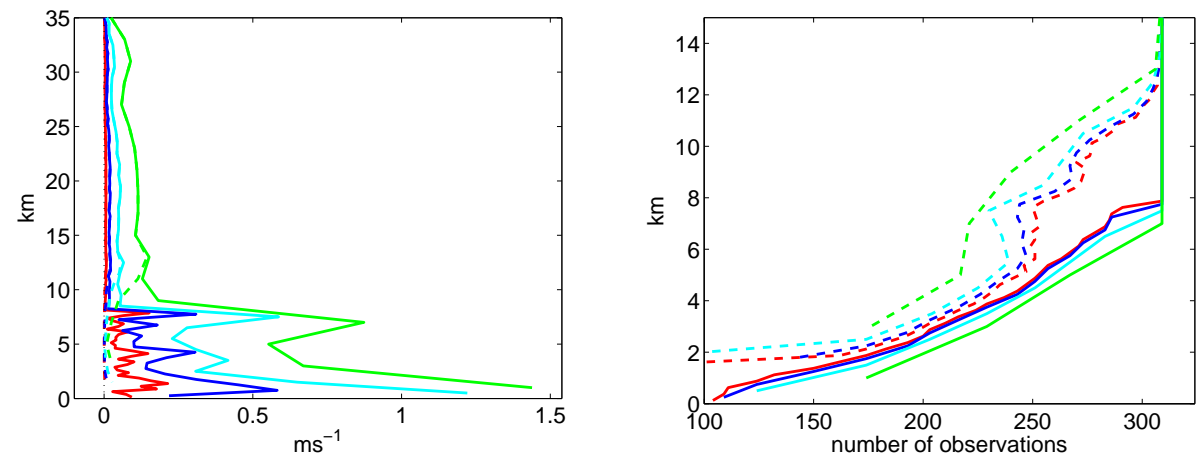

Figure 17. Aeolus Rayleigh wind error standard deviation (left panel) and coverage (right panel) as a function of bin size: $250 \mathrm{~m}$ (red), $500 \mathrm{~m}$ (blue), $1000 \mathrm{~m}$ (cyan) and $2000 \mathrm{~m}$ (green). Dashed and solid lines correspond to processing with and without taking into account signal classification, respectively, see the text for details. The statistics are based on 309 radiosondes launched at 12:00 UTC in De Bilt in 2007. The $y$ axis of the right panel is cut at $15 \mathrm{~km}$, but winds from all 309 launches were obtained up to $35 \mathrm{~km}$.

due to cloud layers that cause a non-homogeneous backscattering from within the measurement bin by molecules, due to cloud extinction. Inside the boundary layer the wind error further increases because of additional non-homogeneous scattering by aerosol. The Rayleigh channel wind errors are substantially smaller than the Mie channel errors, in line with the theoretical analysis of Sect. 3. As for Mie winds, the errors increase with increasing bin size. For typical Rayleigh bin sizes of $1000 \mathrm{~m}$ in the free troposphere the error standard deviation is generally well below $0.5 \mathrm{~m} \mathrm{~s}^{-1}$. This result is further improved through the classification procedure discussed above. The dashed lines in the left panel of Fig. 17 show the Rayleigh wind error standard deviation when using only Rayleigh winds for bins with a scattering ratio below 1.2, i.e. ignoring cloud contaminated bins. Rayleigh channel wind errors then become negligible. This is however at the expense of data coverage as observed from the right panel of Fig. 17: fewer winds are obtained between 2 and $13 \mathrm{~km}$ and no Rayleigh winds are obtained below $2 \mathrm{~km}$ when applying classification. Above $13 \mathrm{~km}$, in the absence of clouds and aerosol, data coverage is identical for all bin sizes and classification is not needed. Note also the convergence of the dashed and solid lines near $13 \mathrm{~km}$ altitude and their overlap above $13 \mathrm{~km}$ in the left panel of Fig. 17.

Rayleigh channel data coverage is also reduced below $8 \mathrm{~km}$ in the absence of classification (solid lines in the right panel). This is because clouds obscure the lower part of the atmosphere. A two-way transmission threshold value of 0.1 was used here, i.e. if the laser signal transmission drops below the threshold value then no valid Rayleigh winds can be retrieved because of too low SNR.

Finally, it should be said that Rayleigh winds meeting the mission requirement in a BRC can only be obtained for bin sizes larger than $1000 \mathrm{~m}$ (Marseille et al., 2013). The red and dark blue curves of Fig. 17 are thus artificial and no valid options for the Rayleigh channel bin size of the Aeolus mission.
Note, however, that smaller vertical bins are useful for a more effective quality control of optically variable scenes.

\section{Summary and conclusions}

The largest spatial variations of the wind generally occur in the vertical, but only few global profile measurements exist today to measure these variations across the globe. The noted variations, i.e. wind shear, cause mixing of air and thus describe the vertical exchange of the associated air properties of momentum, heat, humidity and cloud particles. Indeed, vertical profile of horizontal wind and its shear may indicate dynamical atmospheric processes often associated with cloud formation and significant weather. Such processes generally cause heterogeneous optical properties of the atmosphere, both horizontally and vertically. It remains a challenge to simultaneously measure wind and atmospheric property profiles across the globe.

The ESA Aeolus mission aims to measure wind profiles from space from the received backscatter signal by atmospheric particles (aerosol and cloud) and molecules. However, retrieved winds may suffer from biases induced by instrument imperfections and heterogeneous atmospheric conditions, i.e. varying backscatter and wind inside Aeolus measurement volumes (bins), while observation biases are known to be detrimental when gone undetected in NWP data assimilation. In preparation for Aeolus this study aims to quantify the expected bias in Mie and Rayleigh channel winds caused by vertical atmospheric heterogeneity. In addition recommendations are formulated to identify such scenes and apply quality control to improve level-2B processing before using the observations in NWP.

Realistic assessment of Aeolus wind errors from atmospheric heterogeneity requires a database of combined wind and atmosphere optical properties at substantial higher resolution than the Aeolus observation sampling volume, which is $86 \mathrm{~km}$ along satellite track and several hundreds of metres 
to $2 \mathrm{~km}$ in the vertical. Data from observation sites or available databases either lack resolution or one of the needed database ingredients.

Radiosonde measurements from De Bilt have been used to establish a database of collocated wind and atmospheric optics at $10 \mathrm{~m}$ sampling to simulate atmospheric conditions along Aeolus' lines of sight. The Zhang et al. (2010) method has been adopted to detect clouds along the radiosonde path from measured RH and temperature. Detected clouds are classified based on cloud altitude and temperature. Standard values from the literature are used for cloud backscatter and extinction for each cloud type. For aerosol backscatter and extinction a parameterization was introduced based on climatology and a RH-dependent correction factor.

Detected cloud layers with the Zhang2010 method have been compared against the CloudSat/CALIPSO level-2 cloud mask product for the 2007 1-year period showing good agreement. Comparison against ECMWF model clouds confirms the bias of the ECMWF 2007 model clouds with an underestimate of model clouds below $8 \mathrm{~km}$ and an overestimate of model clouds above $8 \mathrm{~km}$, in agreement with Houchi (2013). Layers of ice clouds over De Bilt are generally thin: $25 \%$ is smaller than $300 \mathrm{~m}, 60 \%$ is smaller than $1 \mathrm{~km}$.

Simulated aerosol backscatter has been compared against real atmospheric measurements in the lower troposphere from the operational UV lidar in Cabauw and shows larger values by a factor of 4 below $700 \mathrm{~m}$ altitude and thus potentially overestimating Aeolus Mie wind coverage in the lower part of the boundary layer. The mean aerosol backscatter variability within $250 \mathrm{~m}$ Aeolus bins in the lower $2 \mathrm{~km}$ of the atmosphere agrees well between both data sets, except for the higher quartile above $500 \mathrm{~m}$ where backscatter variability is underestimated by a factor of 5, implying that wind error biases calculated from the radiosonde database are substantially underestimating those from the real atmosphere.

The derived database from radiosonde launches over De Bilt is unique in the sense that it contains collocated winds and atmospheric optics at high vertical resolution. The database has proven useful for evaluating Aeolus wind biases caused by atmospheric heterogeneity in the vertical. Since radiosondes probe the atmosphere along their path only, additional errors due to horizontal variability (e.g. aerosol and cloud variability due to boundary layer eddies) have been ignored. However, Aeolus' oversampling of the $86 \mathrm{~km}$ along track integration length by 30 measurements enables detection of scenes with large horizontal variability and the application of quality control. Generally, no oversampling is done in the vertical, making Aeolus winds more sensitive to errors from heterogeneity along the laser path.

Rayleigh channel winds are prone to biases when the observation is assigned to the bin centre location because of the non-uniform distribution of molecules inside the measurement bin. Analytical equations were derived to calculate the height assignment error that increases about quadratically with increasing bin size (see Fig. 2). These height assignment errors can be corrected from auxiliary meteorological information, available in the level-2B processor or NWP data assimilation system, that include temperature and pressure profiles at Aeolus locations from ECMWF model forecasts. If not corrected for height assignment errors, Aeolus wind biases are up to $0.5 \mathrm{~m} \mathrm{~s}^{-1}$ in the upper troposphere and lower stratosphere for a typical wind shear of $0.01 \mathrm{~s}^{-1}\left(10 \mathrm{~m} \mathrm{~s}^{-1}\right.$ per $\mathrm{km}$ ), but can be several $\mathrm{m} \mathrm{s}^{-1}$ in dynamically active regions such as near the tropopause and PBL as a consequence of the typically narrow vertical scales near the jet stream. Wind shear climatologies from Marseille et al. (2010) and Houchi et al. (2010) may be used to identify regions that are prone to biases for Aeolus measured winds.

In the case of a cloud or aerosol layer positioned inside the measurement bin, Aeolus provides two wind solutions, one from the Mie channel and one from the Rayleigh channel. Correcting for height assignment errors is not possible when lacking information on the location of the optically enhanced layer inside the bin and on its thickness, yielding errors in retrieved winds when assigned to the bin centre, which appears in itself the most logical choice. The analytical equations from Sect. 3.2 show that errors increase linearly with increasing wind shear in the bin. Wind errors from both channels are smallest for optically thin layers, i.e. with layer transmission close to 1. Errors increase with decreasing transmission. Wind errors from both channels decrease for increasing layer thickness at given layer transmission (see the bottom row of Fig. 3). Mie channel wind errors are relatively sensitive to the layer thickness but insensitive to the layer transmission. The reverse is true for Rayleigh channel winds. This makes Rayleigh channel winds potentially more reliable because layer transmission can be calculated from the measured signals by the optical properties code, under development, as part of the L2Bp.

Mie channel wind biases generally exceed the mission requirement of $0.4 \mathrm{~m} \mathrm{~s}^{-1}$. For a $1000 \mathrm{~m}$ bin size, a typical windshear of $0.01 \mathrm{~s}^{-1}$ and a common thin cloud layer the bias can be up to $2.85 \mathrm{~m} \mathrm{~s}^{-1}$, irrespective of cloud type which is substantially larger than the random error of typically $1 \mathrm{~m} \mathrm{~s}^{-1}$. In addition, such systematic errors may extend over many observations, depending on the size of the cloud/aerosol layer, and are known to be detrimental for NWP if not properly treated. Reducing the Mie bin size alleviates this problem. Rayleigh channel wind solutions have much smaller biases and are within the mission requirement for transparent cloud or aerosol layers with one-way transmission exceeding 0.8 .

The analytical equations were largely confirmed by calculations from the radiosonde database:

- Rayleigh channel height assignment errors calculated from the database are slightly larger and relatively insensitive to temperature and pressure errors in the L2Bp auxiliary meteorological data; 
- the wind error standard deviation grows linearly with increasing bin size;

- typical values for the Mie channel wind RMSE in the free troposphere are in the range $1-1.5 \mathrm{~m} \mathrm{~s}^{-1}$ for 1000 $\mathrm{m}$ bins, i.e. slightly below the mean RMSE value of $1.66 \mathrm{~m} \mathrm{~s}^{-1}$ from the bottom left panel of Fig. 3;

- Rayleigh channel wind errors through atmospheric heterogeneity are substantially smaller than Mie channel wind errors. For $1000 \mathrm{~m}$ bins, the error standard deviation (from the cyan solid line in the left panel of Fig. 17) is about $0.1 \mathrm{~m} \mathrm{~s}^{-1}$ in the stratosphere (molecules only), between 0.2 and $0.6 \mathrm{~m} \mathrm{~s}^{-1}$ in the free troposphere (negligible aerosols but cloud presence) and exceeding $1 \mathrm{~m} \mathrm{~s}^{-1}$ in the PBL (aerosol and/or cloud presence). The mean value of the middle right panel of Fig. 3 equals $0.4 \mathrm{~m} \mathrm{~s}^{-1}$, i.e. within the range of the above values for atmospheric scenes with cloud layers in the free troposphere.

It is noted that Rayleigh wind error biases due to atmospheric particles can be largely reduced by the classification procedure that is implemented in the Aeolus L2Bp which selects measurements classified as particle-free before integrating to observation level. The reduced bias is at the expense of an increased random error and reduced data coverage, but the latter two are much less detrimental for NWP than systematic errors.

From the above it is clear that the L2Bp classification procedure is of vital importance to reduce wind error biases (Rayleigh channel) and to detect winds with potential large biases that cannot be corrected for (Mie channel) and need special treatment before use in data assimilation, e.g. reducing their weight in the analysis or rejection. For Rayleigh channel bins, classification can be applied only in the case of a corresponding Mie bin at the same altitude, which may not always be available, depending on the Mie and Rayleigh channel sampling strategy (Marseille et al., 2010). More advanced classification procedures are foreseen that rely on the Rayleigh channel signal only for instance to detect tropical cirrus and polar stratospheric clouds in the case of missing Mie bins or Mie channel failure. Moreover, it is foreseen that the Mie channel oversamples the Rayleigh channel, and that more accurate correction of the Rayleigh winds will be feasible.

Not only errors due to horizontal atmospheric heterogeneity are ignored here, but also errors due to cloud dynamics, while cloud dynamics do directly contribute to unrepresentative winds for NWP data assimilation and thus larger Aeolus observation errors.

The method to establish a radiosonde database may be applied to radiosondes in other climate zones to assess Aeolus wind errors for typical atmospheric conditions such as in the (sub-)tropics. The location, thickness and composition of cloud layers is important for many reasons, among others for atmospheric radiation and latent heat fluxes, for the validation of NWP models and for the validation of cloud products derived from geostationary satellites, including the height assignment of atmospheric motion wind vectors derived from time series of satellite cloud images.

Moreover, more realistic optical profiles may be obtained by developing a relationship between the radiosonde temperature and humidity profile with the cloud liquid water and cloud ice profiles; the latter are directly related to atmospheric backscatter properties. This remains future work.

Acknowledgements. This study is supported by the National Natural Science Foundation of China (Grant No. 41205125). We would like to thank the Royal Netherlands Meteorological Institute (KNMI) for providing the Radiosonde RS92, the UV lidar and ECMWF model data sets. The CloudSat/CALIPSO data are provided by the NASA CloudSat project from their web site at http://www.cloudsat.cira.colostate.edu. The authors thank the two anonymous referees for their valuable comments.

Edited by: P. Xie

\section{References}

Ackermann, J.: The extinction-to-backscatter ratio of tropospheric aerosol: a numerical study, J. Atmos. Ocean. Tech., 15, 10431050, 1998.

Alduchov, O. A. and Eskridge, E. E.: Improved Magnus form approximation of saturation vapor pressure, J. Appl. Meteorol., 35, 601-609, 1996.

Ansmann, A., Ingmann, P., Le Rille, O., Lajas, D., and Wanginger, U.: Particle backscatter and extinction profiling with the spaceborne HSR Doppler wind lidar ALADIN, Proc. of 23rd Int. Laser Radar Conf. (ILRC), Nara, Japan, 1015-1018, 2006.

Chernykh, I. V. and Eskridge, R. E.: Determination of clouds amount and level from radiosonde soundings, J. Appl. Meteorol., 35, 1362-1369, 1996.

ESA: ADM-Aeolus science report, avialable at: http://esamultimedia.esa.int/docs/SP-1311_ ADM-AeolusFINALlow-res.pdf (last access: 10 February 2014), 2008.

Evans, B. T. N.: Sensitivity of the backscatter/extinction ratio to changes in aerosol properties: implications for lidar, Appl. Optics, 27, 3299-3305, 1988.

Fernald, F. G.: Analysis of atmospheric lidar observations: some comments, Appl. Optics, 23, 652-653, 1984.

Gasso, S., Hegg, D. A., Covert, D. S., Collins, D., Noone, K. J., Oström, E., Schmid, B., Russel, P. B., Livingston, J. M., Durkee, P. A., and Josson, H.: Influence of humidity on the aerosol scattering coefficient and its effect on the upwelling radiance during ACE-2, Tellus B, 52, 546-567, 2000.

Groß, S., Tesche, M., Freudenthaler, V., Toledano, C., Wiegner, M., Ansmann, A., Althausen, D., and Seefeldner, M.: Characterization of Saharan dust, marine aerosols and mixtures of biomassburning aerosols and dust by means of multi-wavelength depolarization and Raman lidar measurements during SAMUM 2, Tellus B, 63, 706-724, 2011. 
Guerrero-Rascado, J. L., Costa, M. J., Bortoli, D., Silva, A. M., Lyamani, H., and Alados-Arboledas, L.: Infrared lidar overlap function: an experimental determination, Optics Express, 18, 2035020359, 2010.

Houchi, K.: On high resolution wind, shear and cloud vertical structures - preparation of the Aeolus space mission, PhD. Thesis, University of Technology, Eindhoven, the Netherlands, 2013.

Houchi, K., Stoffelen, A., Marseille, G. J., and de Kloe, J.: Comparison of wind and wind shear climatologies derived from highresolution radiosondes and the ECMWF model, J. Geophys. Res., 115, D22123, doi:10.1029/2009JD013196, 2010.

Klett, J. F.: Lidar inversion with variable backscatter/extinction ratios, Appl. Optics, 24, 1638-1643, 1985.

Lazarus, S. M., Krueger, S. K., and Mace, G. G.: A cloud climatology of the Southern Great Plains ARM CART, J. Climate, 13, 1762-1775, 2000.

Liu, Z., Sugimoto, N., and Murayama, T.: Extinction-to-backscatter ratio of Asian dust observed with high-spectral-resolution lidar and Raman lidar, Appl. Optics, 41, 2760-2766, 2002.

Liu, Z., Omar, A. H., Hu, Y. X., Vaughan, M. A., and Winker, D. M.: CALIOP algorithm theoretical basis document, part 3: Scene classification algorithms, available at: http://www-calipso. larc.nasa.gov/resources/pdfs/PC-SCI-202_Part3v1.0.pdf (last access: 10 February 2014), 2005.

Mace, G. G., Marchand, R., Zhang, Q., and Stephens, G. L.: Global hydrometeor occurrence as observed by CloudSat: Initial observations from summer 2006, Geophys. Res. Lett., 34, L09808, doi:10.1029/2006GL029017, 2007.

Marseille, G. J. and Stoffelen, A.: Simulation of wind profiles from a space-borne Doppler wind lidar, Q. J. Roy. Meteorol. Soc., 129, 3079-3098, 2003.

Marseille, G. J., Stoffelen, A., and Barkmeijer, J.: Sensitivity Observing System Experiment (SOSE) - a new effective NWPbased tool in designing the global observing system, Tellus A, 60, 216-233, 2008.

Marseille, G. J., Stoffelen, A., Schyberg, H., Körnich, H., and Megner, L.: VAMP - vertical Aeolus measurement positioning, ESA study final report, Contract 20940/07/NL/JA, ESA, Noordwijk, the Netherlands, 2010.

Marseille, G. J., Houchi, K., de Kloe, J., and Stoffelen, A.: The definition of an atmospheric database for Aeolus, Atmos. Meas. Tech., 4, 67-88, doi:10.5194/amt-4-67-2011, 2011.

Marseille, G. J., Stoffelen, A., Schyberg, H., Körnich, H., and Megner, L.: VHAMP - vertical and horizontal Aeolus measurement positioning, ESA study final report, CCN2 to Contract 20940/07/NL/JA, ESA, Noordwijk, the Netherlands, 2013.

Müller, D., Ansmann, A., Mattis, I., Tesche, M., Wandinger, U., Althausen, D., and Pisani, G.: Aerosol-type-dependent lidar ratios observed with Raman lidar, J. Geophys. Res., 112, D16202, doi:10.1029/2006JD008292, 2007.

Onasch, T. B., Siefert, T. L., Brooks, S. D., Prenni, A. J., Murray, B., Wilson, M. A., and Tolbert, M. A.: Infrared spectroscopic study of the deliquescence and efflorescence of ammonium sulfate aerosol as a function of temperature, J. Geophys. Res., 104, 21317-21326, 1999.
Paffrath, U., Lemmerz, C., Reitebuch, O., Witschas, B., Nikolaus, I., and Freudenthaler, V.: The airborne demonstrator for the directdetection Doppler wind Lidar ALADIN on ADM-Aeolus, Part II: Simulations and Rayleigh receiver radiometric performance, J. Atmos. Ocean. Tech., 26, 2516-2530, 2009.

Poore, K. D., Wang, J. H., and Rossow, W. B.: Cloud layer thicknesses from a Combination of surface and upper-air obversions, J. Climate, 8, 550-568, 1995.

Reitebuch, O., Lemmerz, C., Nagel, E., Paffrath, U., Durand, Y., Endemann, M., Fabre, F., and Chaloupy, M.: The airborne demonstrator for the direct-detection Doppler wind lidar ALADIN on ADM-Aeolus, Part I: Instrument design and comparison to satellite instrument, J. Atmos. Ocean. Tech., 26, 2501-2515, 2009.

Rogers, R. M., McCann, K., and Hoff, R. M.: Quantifying the effect of humidity on aerosol scattering with a Raman lidar, 14th Joint Conference on the Applications of Air Pollution Meteorology with the Air and Waste Management Assoc., Atlanta, Georgia, 2006.

Schillinger, M., Morancais, D., Fabre, F., and Culoma, A. J.: ALADIN: the LIDAR instrument for the AEOLUS mission, Proc. SPIE, 4881, 40-51, 2003.

Spinhirne, J. D., Chudamani, S., Cabanaugh, J. F., and Bufton, J. L.: Aerosol and cloud backscatter at $1.06,1.54$, and $0.53 \mu \mathrm{m}$ by airborne hard-target-calibrated Nd:YAG/methane Raman lidar, Appl. Optics, 36, 3475-3489, 1997.

Stoffelen, A., Pailleux, J., Källén, E., Vaughan, J. M., Isaksen, L., Flamant, P., Wergen, W., Andersson, E., Schyberg, H., Culoma, A., Meynart, M., Endemann, M., and Ingmann, P.: The Atmospheric dynamics mission for global wind measurement, B. Am. Meteorol. Soc., 86, 73-87, 2005.

Stoffelen, A., Marseille, G. J., Bouttier, F., Vasiljevic, D., de Haan, S., and Cardinali, C.: ADM-Aeolus doppler wind lidar observing system simulation experiment, Q. J. Roy. Meteorol. Soc., 132, 1927-1947, doi:10.1256/qj.05.83, 2006.

Tan, D. G. H., Andersson, E., Fisher, M., and Isaksen, L.: Observing system impact assessment using a data assimilation ensemble technique: Application to the ADM-Aeolus wind profiling mission, Q. J. Roy. Meteorol. Soc., 133, 381-390, 2007.

Tan, D. G. H., Andersson, E., de Kloe, J., Marseille, G. J., Stoffelen, A., Poli, P., Denneulin, M. L., Dabas, A., Huber, D., Reitebuch, O., Flamant, P., Rille, O. L., and Nett, H.: The ADM-Aeolus wind retrieval algorithms, Tellus A, 60, 191-205, 2008.

Vaisala: Vaisala RS92 Number One in WMO Intercomparison, available at: http://www.vaisala.com/Vaisala\% 20Documents/Vaisala\%20News\%20Articles/VN186/vn186_ 04vaisala-rs92-number-one-in-wmo-intercomparison.pdf (last access: 10 February 2014), 2011.

Vaughan, J. M.: Scattering in the atmosphere, in: Scattering and Inverse Scattering in Pure and Applied Science, edited by: Pike, E. R. and Sabatier, P. C., Academic Press, San Diego, 2002.

Vaughan, J. M., Geddes, N. J., Flamant, P. H., and Flesia, C.: Establishment of a backscatter coefficient and atmospheric database, ESA contract 12510/97/NL/RE, ESA, Noordwijk, the Netherlands, p. 110, 1998.

Vogelzang, J., Stoffelen, A., Verhoef, A., and Figa-Saldana, J.: On the quality of high-resolution scatterometer winds, J. Geophys. Res., 116, C10033, doi:10.1029/2010JC006640, 2011. 
Wang, J. H. and Rossow, W. B.: Determination of cloud vertical structure from upper-air observations, J. Appl. Meteorol., 34, 2243-2258, 1995.

Winker, D. M.: The CALIPSO Mission and Initial Observations of Aerosols and Clouds from CALIOP, Proc. SPIE, 6409, 1-3, 2006.
Zhang, J. Q., Chen, H. B., Li, Z. Q., Fan, X. H., Peng, L., Yu, Y., and Cribb, M.: Analysis of cloud layer structure in Shouxian, China using RS92 radiosonde aided by $95 \mathrm{GHz}$ cloud radar, J. Geophys. Res., 115, D00K30, doi:10.1029/2010JD014030, 2010. 